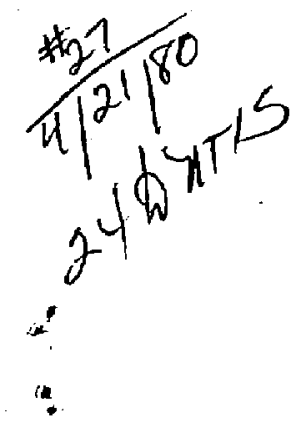

UCID- 17980 , Rev. 1

\title{
MASTER
}

TACO - A FINITE ELEMENT HEAT TRANSFER CODE

W. E. Mason, Jr.

\section{February 1980}

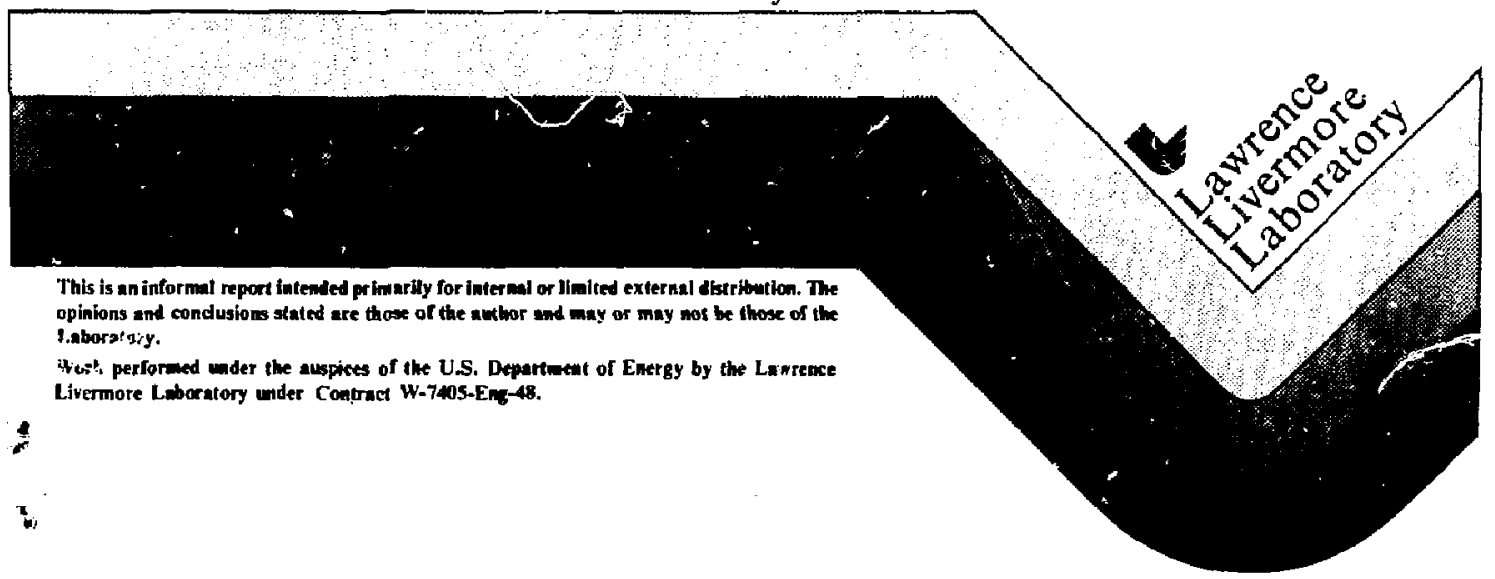

DISTRIBUTTOH OF THIS OOCUMENT IS UHLIKITED 
1. INTRODUCTION ......................

2. GENERAL DESCRIPTION . . . . . . . . . . . . . . . 2

2.1 BASIC EQUATIONS . . . . . . . . . . . . . . . . 3

2.2 FINITE ELEMENT FORMULATION . . . . . . . . . . . . . 4

2.3 TIME INTEGRATION SCHEME . . . . . . . . . . . . . it

2.4 LINEAR SOLUTION SCF EME . . . . . . . . . . . . . . . . . 6

2.5 NONLINEAR SOLUTION SCHEME . . . . . . . . . . . . . 7

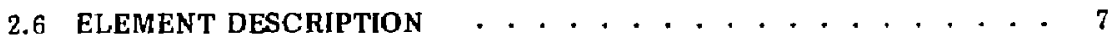

2.7 MATERIAL PROPERTIES . . . . . . . . . . . . . 8

2.8 INTERNAL HEAT GENERATION . . . . . . . . . . . . . . 8

2.9 INITIAL CONDITIONS . . . . . . . . . . . . . . . 8

2.10 BOUNDARY CONDITIONS . . . . . . . . . . . . . . o

2.11 INTERNAL SURFACE CONDITIONS . . . . . . . . . . . . . . 9

2.12 BULK NODES . . . . . . . . . . . . . . . 10

2.13 ENCLOSURE RADIATION . . . . . . . . . . . . . 11

2.14 FUNCTION DEFINITIONS . . . . . . . . . . . . . 12

2.15 USER SUBPROGRAM . . . . . . . . . . . . . . 13

2.16 PHASE CHANGES . . . . . . . . . . . . . . . . . 13

2.17 CHEMICAL KINETICS . . . . . . . . . . . . . . . 15

2.18 UNITS . . . . . . . . . . . . . . . . 15

2.19 TRANSIENT ANALYSIS . . . . . . . . . . . . . 16

2.20 STEADY STATE ANALISIS . . . . . . . . . . . . . . 16

2.21 MESH GENERATION . . . . . . . . . . . . . . . . . 16

2.22 BANDWITH AND PROFI $L E$ MINIMIZATION . . . . . . . . . 17

2.23 POST PROCESSING . . . . . . . . . . . . . . . . . 17

2.24 THERMAL STRESS ANALYSIS . . . . . . . . . . . . . 17

3. A V AILABILITY . . . . . . . . . . . . . . . . 18

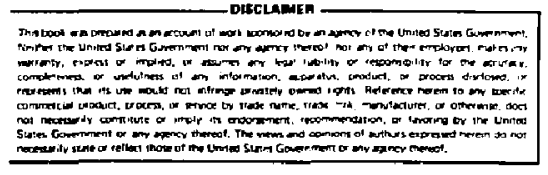

$-\mathrm{ii}-$ 
4. EXECUTION ........................... 19

5. USER'S GUIDE . . . . . . . . . . . . . . . . . $\mathrm{z} 1$

5,1 TITLE CARD ....................... 21

5.2 CONTROL CARDS .................. 22

5.3 NODAL POINT DATA .............. 30

5.4 ElemENT DATA . . . . . . . . . . . . . 31

5.5 MATERIAL PROPERTY DATA . . . . . . . . . . . . 32

5.6 HEAT GENERATION DATA . . . . . . . . . . . 35

5.7 INITIAL TEMPERATURE DATA . . . . . . . . . . . . . 36

5.8 NODAL TEMPERATURE SPECIFICATION . . . . . . . . . . 37

5.9 FLUX BOUNDARY CONDITION DATA . . . . . . . . . . . . . 38

5.10 CON VECTION BOUNDARY CONDITION DATA . . . . . . . . 40

5.11 GENERAL NONLINEAR BOUNDARY CONDITION DATA . . . . . 42

5.2 INTERNAL SURFACE CONDITION DATA . . . . . . . . . . 44

5.13 BULK NODE DATA . . . . . . . . . . . . . . . . 46

5.14 ENCLCSURE RADIATION DATA . . . . . . . . . . . 49

5.15 PIECEWISE LINEAR CURVE DETA ............. 53

5.16 BLOCK TIME STEP OPTION . . . . . . . . . . . . . . . . 54

5.17 "NEWFILE" OPTION . . . . . . . . . . . . . . . . . 55

S.1B INTERACTIVE CNNTROLS ............. 56

6. EXAMPLES . . . . . . . . . . . . . . . . . . 57

6.1 EXAMPle No. 1................... 57

G.2 EXAMPLE No. $2 . . . . . . . . . . . . . .660$

7. ACKNOWLEDGEMENT ...................... 66

8. REFERENCES ...................... 67 APPENDICIES

A. USER SUBPROGRAM . . . . . . . . . . . . . 68

B. ENClOSURE RADIATION ................ 71

C. Plot file data base . . . . . . . . . . . . . . 75 


\section{TACO - A FINITE ELEMENT HEAT TRANSFER CODE}

\section{INTRODUCTION}

Taro is a two-dimensionnl implicit finite element code for heat transfer analysis. It ean perform both lincar and nonlinear analyses and can be used to solve either transient or steady state problems, Fither plane or axisymmetric geometries can be analyzed.

TACO has the capability to handle time or temperature dependent material properties and materials nav be either isotropic or orthotropic. A variety of time and temperature dependent loadings and boundary conditions are available including temperature, flux, convection, and radiation boundary conditions and internal heat generation.

Idditionally, TACO has some specialized features such as internal surface eonditions (e.g., contact resistance), hulk nodes, enclosure radiation with view factor calculations, and chemical reactive kineties. A user subprogram feature allows for any type of functional representation of any independent variable. A bandwidth and profile minimization option is also nvailable in the code.

Graphical representation of data generate; by TAC.O is provided bu a companion pnst-processor named POSTACO (1).

The following sections outline the basic theory on which TACO is based, explain the capabilities of the code, and describe the iriput data required to perform an analysis with TACO. Some simple examples are provided to illustrate the use of the code. 


\section{GENERAL DESCRIPFION}

\subsection{BASIC EQUATIONS}

The basic heat transfer problem for which TACO is designed is that of transient nonlinear conduction which can be deseribed by the differential equation

$$
\rho c_{p} \dot{\theta}=\left(k_{i j} \theta_{, j}\right)_{i}+Q \quad \text { in } R
$$

with boundary conditions

$$
\theta=\theta_{\mathrm{s}} \quad \text { on } \mathrm{s}_{1}
$$

and

$$
k_{i j} \theta_{j} n_{i}+q=0 \quad \text { on } s_{2}
$$

and with the initial condition

$$
\theta=\theta_{0} \quad \text { at } \mathbf{t}=\mathbf{t}_{\mathbf{0}}
$$

where $R$ is the region of interest contained within boundary surface $S=S_{1}+S_{2}$. In these equations, commas are used to denote spatial derivatives and a dot denotes a partial derivative with respect to time. Index notation is used with the summation convention (repeated indices imply summation). The various quantities in these equations are defined as follows:

$$
\begin{array}{ll}
\theta=\theta\left(x_{i}, t\right) & =\text { temperature } \\
x_{i} & =\text { spatial coordinates } \\
t & =\text { time } \\
\rho \quad=\rho\left(x_{i}\right) & =\text { density } \\
c_{p}=c_{p}\left(x_{i}, \theta, t\right) & =\text { specific heat } \\
k_{i j}=k_{i j}\left(x_{i}, \theta, t\right) & =\text { thermal conduetivity } \\
Q=Q\left(x_{i}, \theta, t\right) & =\text { internal heat generation rate }
\end{array}
$$




$$
\begin{aligned}
& \theta_{s}=\theta(s, t) \\
& q=g(s, \theta, t) \\
& n_{j} \\
& \theta_{0}=\theta_{0}\left(x_{i}\right) \\
& t_{0}
\end{aligned}
$$

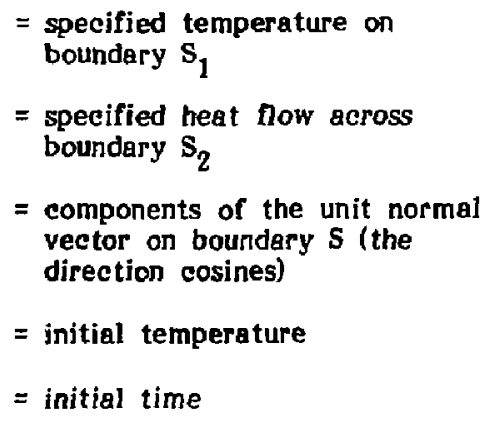

The boundary heat flow $q$ can be expressed in the general nonlinear form

$$
\mathrm{g}=\sum \mathrm{f}(\theta, \mathrm{t})\left(\theta^{\mathrm{a}}-\theta_{\mathrm{q}}^{\mathrm{a}}\right)^{\mathrm{b}}
$$

where $f, a, b$ and $\theta_{\mathrm{q}}$ depend on the type of boundary condition being specified. The summation sign indicates that more then one type of condition may be specified at a point on the boundary (e.g., radiation and convection). Equation (5) may be "linearized" into the form

$$
\mathbf{q}=\mathbf{f}_{0}(\theta, \mathrm{t})+\mathrm{h}(\theta, \mathrm{t})\left(\theta-\theta_{\mathbf{q}}\right)
$$

where the $f_{0}$ term allows for the cese where $a=b=0$ in Eq. (5) (i.e., a flux boundary condition).

\subsection{FINITE ELEMENT FORMULATION}

In order to formulate the above problem in terms of the finite element method (2), one can proceed as follows: First the region $R$ is subdivided into a series of $51^{\circ}$ egions or elements within which the temperature is approximated by

$$
\theta\left(x_{i}, t\right)=\sum_{j} N_{j}\left(x_{i}\right) \theta_{j}(t)
$$

where $\theta_{j}(t)$ are the element nodal point temperatures and $N_{j}\left(x_{i}\right)$ are the element interpolation functions. 
Next, the Galerkin principle (2) is utilized to obtain the element heat capacity and conductivity matrices and element thermal loed vector which can be represented respectively by

$$
\begin{aligned}
& C_{i j}=\int_{V} N_{i} p c_{p} N_{j} d V \\
& K_{i j} \int_{V} N_{i, \alpha}{ }^{k} \alpha \beta N_{j, g} d V+\int_{S_{2}} N_{i} h N_{j} d S \\
& F_{i}=\int_{V} N_{i} Q d V+\int_{S_{2}} N_{i}\left(h \theta_{q}-f_{0}\right) d S
\end{aligned}
$$

where the volume and surface integrals are over each element.

Appropriate combination of the element matrices yields the system equation

$$
\mathbf{C} \dot{\theta}+\mathbf{K} \theta=\mathbf{F}
$$

where

$\mathrm{C}=$ system heat capacity matrix

$K=$ system conductivity matrix

$F=$ thermal loed vector

$\theta=:$ vector of nodal point temperatures

$\dot{\theta}=$ vector of time derivatives of nodal point temperatures

\subsection{TIME INTEGRATION SCHEME}

The time integration of Equation (11) is carried out in TACO using a generalized midpoint method (3) which is formulated as follows:

$$
C_{t+a \Delta t} \dot{\theta}_{t+\alpha \Delta t}+k_{t+a \Delta t} \theta_{t+\alpha \Delta t}=F_{t+\alpha \Delta t}
$$


where

$$
\begin{aligned}
& \theta_{t+a \Delta t}=(1-a) \theta_{t}+\alpha \theta_{t+\Delta t} \\
& \theta_{t+\Delta t}=\theta_{t}+\Delta \theta_{t} \\
& \dot{\theta}_{t+\alpha \Delta t}=\left(\theta_{t+\Delta t}-\theta_{t}\right) / \Delta t \\
& C_{t+a \Delta t}=C\left(\theta_{t+a \Delta t}\right) \\
& K_{t+a \Delta t}=K\left(\theta_{t+a \Delta t}\right) \\
& F_{t+a \Delta t}=(1-a) F_{t}+\alpha F_{t+\Delta t}
\end{aligned}
$$

Substituting Equations (12-18) into Equation (11) and rearranging gives the following equation for $\Delta \theta_{\mathrm{t}}$ :

$$
\mathbf{K}_{\mathrm{t}+\boldsymbol{\alpha} \Delta \mathrm{t}}^{*} \Delta \theta_{\mathbf{t}}=\mathbf{F}_{\mathrm{t}+\mathbf{\alpha} \Delta \mathrm{t}}^{*}
$$

where

$$
\begin{aligned}
& K_{t+\alpha \Delta t}^{*}=\frac{C_{t+\alpha \Delta t}}{\Delta t}+\alpha K_{t+\alpha \Delta t} \\
& F_{t+\alpha \Delta t}^{*}=F_{t+\alpha \Delta t}-K_{t+a \Delta t} \theta_{t}
\end{aligned}
$$

The parameter $a$ in the above equations must be limited to $0 \leq a \leq 1$. In terms of classical procedures, $\alpha=0$ gives the forward explicit method, $\alpha=\frac{1}{2}$ results in the Crank-Nicholson method, and $\alpha=1$ gives the backward implicit method. For $\frac{1}{2} \leq \alpha \leq 1$, the procedure is unconditionally stable. For $0 \leq a<\frac{1}{2}$, the procedure can be unstable if the time step is too large. It is, therefore, recommended that $a$ be selected in the range $\frac{1}{2} \leq \alpha \leq 1$. The code uses $\alpha=\frac{1}{2}$ as the default value. 
For steady state gnalysis. Fquation (11) reduces to

$$
\mathrm{K} \theta=\mathrm{F}
$$

which requires oniy a one step solution.

\subsection{LINEAR SOLUTION SCHEME}

In a linear problem, the solution proceriure is to simply march along in time solying Equation (19) for $\Delta \theta_{t}$ at each time step. This $\Delta \theta_{t}$ is then added to the previous $\theta_{t}$ to update the nodal temperatures. A new $F^{*}$ vector must be formed at each time step. However, the effective conductivity matrix $K^{*}$ need only be reformed if the time step size $\Delta t$ changes.

Equation (19) represents a system of linear algebraic equation; which is symmetric and in band or profile form. The equations are solved in TACO by an efficient, out-of-core, direct, block profile solver (6).

\section{$2.5 \quad$ NONLINEAR SOLUTION SCHEME}

In a nonlinear problem, both $\mathbf{K}^{*}$ and $\mathbf{F}^{*}$ may be functions of $\theta$ and thus iteration must be used to solve Equation (19). Two iteration methods are available in 7'ACO to solve such equations. The first is the direct iteration method wherein $K^{*}$ is reformed and, thus, necessarily reduced for each iteration. The second, a modified direct iterution method does not reform $K^{*}$ for each iterate but uses the initial $K^{*}$ caleulated at the first iteration within the time step. The direct iteration method converges more rapidly than the modified method but each iteration requires more computation. TACO also allows combinations of the two methods to be used. The decision as to which method or combination of methods is best to use on a particular problem must be made based on user 
experience or a trial-and-error process. In addition, for problems where $\mathrm{K}^{*}$ changes slowly with temperature and where $\Delta t$ does not eliange, $\mathrm{T} A \mathrm{CO}$ has the option to use the same $\mathrm{K}^{*}$ over several time steps.

\subsection{ELEMEN'T DESCRIPTION}

Presently TACO utilizes a four node isopa:'ametric element for interior regions. This element degenerates to a three node triangle when two nooe numbers of the four node element are identical (see figure).
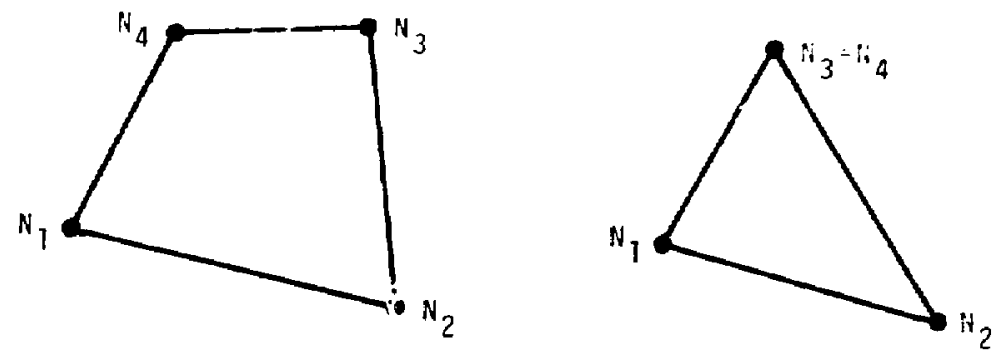

\subsection{MATERIAL PRCPERTIES}

The density, specific hea!, and thermal condurtivity are assumed to be spatiylly

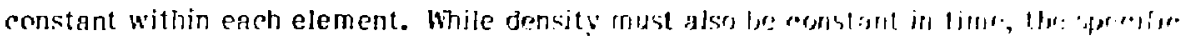
leat and conductivity may be functions of cither time or temperiatim. In ardition, the thermal conductivity may be either isotropic or orthotropic. TACO allows an arbitrary number of different materials to be specified. Carried to the extreme, egeh element could be composed of a different material. 


\subsection{INTERNAL HEAT GENERATION}

Internal heat generaticn rates can be funetions of tim- or temperature. Spatially, they are assumed constant within an element. Heat generation may be specified by element, by material, or both (in which case the effect is additive).

\section{$3.9 \quad$ INITIAL CONDITIONS}

Initial temperatures may be specified in TACO by either a single constant value over the entire body or by different values assigned to each nodal point. In cases where it is desired to specify initial temperatures which are discontinuous across element interfaces, the user must average the temperatures at the interfaces for specification at the nodal points defining the interfaces.

\subsection{BOUNDARY CONDITIONS}

As indicated in Section 2.1 , boundary conditions can be specified as either temperature (Eq. 2) or heat flow (Eg. 3). Temperature "thoundary conditions" can be specified as functions of time at anv node whether on the physical boundary or not.

Heat flow boundary conditions can, as explained earlier, take the general form

$$
q=(\theta, t)\left(\theta^{a}-\theta_{q}^{a}\right)
$$

and can be specified more than once over the same surface such as in a case of, say, combined radiation and convection. Heat flow boundary conditions can be specified on any "surface" (element boundary). 
Equation (23) can be specialized to several standard types of boundary conditions.

The following examples help to illustrate this.

1. Flux: $q=q_{\mathbf{f}}$

Set $f=q_{f}, q=1$, and $h=\theta_{q}=0$.

2. Foreed Convection: $q=h(\theta, t)\left(\theta-\theta_{\infty}\right)$

Set $f=h, a=b=i$, and $\theta_{Q} ; \theta_{\infty}$ wliere $h$ is the convection heal transfer coeffir.iant and $\theta_{\infty}$ is the equilibom tempersture.

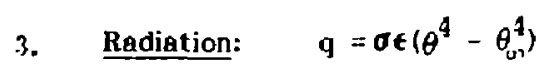

Set $\mathrm{r}=\sigma \epsilon, \mathrm{a}=4, \mathrm{~b}=1$, and $\theta_{\mathrm{q}}=\theta_{\infty}$ where $\sigma$ is the Stefan-Boltzmann constant, $\mathrm{c}$ is the surface eraissivity, and $\theta_{\infty}$ is the equilibrium temperature.

Ir addition to houndary conditions of the general form of Eq. (23), TACO allows for direet specification of the flux and furced convection boundary conditions (s a sections 5.9 and 5.10).

For situations where it is desired to specify adiabatic $(q=0)$ consitions such as at an insulated surface or on a line of symmetry, no boundary condition need be specified. This is the default condition in TACO; i.e., if no boundary condition is specified on a surface, it is $r$ ssumed to be $q=0$.

\subsection{INTERNAL SURFACE CONDITIONS}

It is possible in TACO to spunify conditions between internal surfaces which are of the same form as the general external boundary conditions described in the previous section. In this case the general form is

$$
q=f(\theta, t)\left(\theta_{A}^{a}-\theta_{B}^{a}\right)^{b}
$$


where subscripts $A$ and B refer to the "element" segments as indicated in the following figure

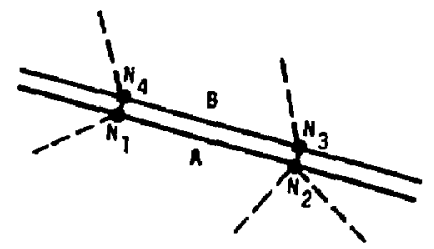

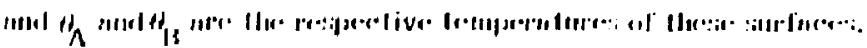

This type of "internal surface condition" is suitable for specifying contact resistances between surfaces and for deseribing certain types of "gap" elements.

While four node numbers are required to define this type of "surface condition", opposed nodal coordinates may coincide. That is, an "elenient" may have zero thickness.

\subsection{BULK NODES}

The bulk node concept is best deseribed with the aid of the following figure:

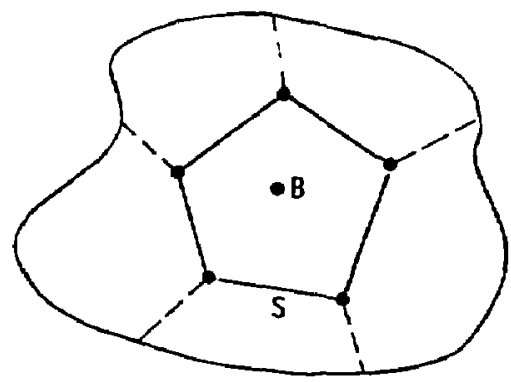


Here a bulk node "B" is used to represent the entire volume of a particular material such as a gas in a cavity. The heat flow between the bulk node (material) " $\mathrm{B}$ " and an adjoining surface " $\mathrm{S}$ " is given, in general, by

$$
\mathrm{q}=\mathrm{f}(\theta, \mathrm{t})\left(\theta_{\mathrm{S}}^{\mathrm{a}}-\theta_{\mathrm{B}}^{\mathrm{a}}\right)^{\mathrm{h}}
$$

where $A$ and $\theta_{B}$ represent the temperatures of the surface " $S$ " and the bulk node " $B$ " respcetively. In addition, the density, specific heat and volume of the bulk material are specified.

Equation (25) is of the same general form as Equation (23) and (24) in the preceding two sections and can be specialized to specific cases in the same manner as described in Section 2.10 .

TACO requires that a bulk node be given a node number as well as coordinates. However, these coordinates in general are arbitrary.

The bulk node concept ean also be used in the case where it is desired to specify a lumped heat capacity at a node. In such a case, no segments "S" are associated with the bulk node and only the density, heat capacity and volume associated with the bulk node are specified.

\subsection{ENCLOSURE RADIATION}

TACO has the capability of soiving problems of diffuse gray body radiation in an enclosure coupled with conduction in the material surrounding the enclosure. For convenience, TACO calculates the necessary view factors internally so that data preparation and input are minimized. However, the option to input view factors is available should the user desire. 
A detailed discussion of the enclosure radiation capabilities of TACO is contriner in Anpendix B.

\subsection{FUNCTION DEFINITIONS}

Anv specified function of time or temperature (i.e., material properties, thermal loadings, houndary conditions) can be described by either piecewise linear curve or hv a functional relationshio defined in a user suhorogram.

A typical piecewise linear curve is shown below.

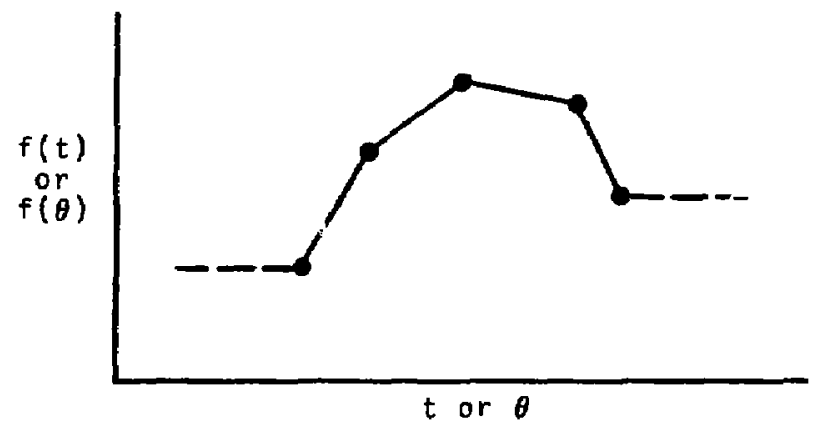

Values of a function at intermediate points on a curve are obtained by linear interpolation. Functional values outside the range of a curve are extrapolated as constants (dashed lines).

Except for the case of specific heat and conductivity a single curve may be used for several functions if their ordinates differ by only a constant. This is accomplished hy the use of curve multipliers which are applied to the ordinate of the curve. 
In order to differentiste between a function of time and a function of temperature, the sign on the number assigned to the curve describing the function is used. For $\theta$ time variation, the curve number is positive and for a temperature variation, the curve number is preceded by a negative sign. A curve number of zero indicates that a function is constant.

If it is desired to use a functional representation other than a piecewise linear curve, the user subprogram option can be used. This option is deseribed in the next section.

\subsection{USER SUBPROGRAM}

A user subprogram option is available in TACO whereby any type of functional relationship(s) inay be defined. In this casn, the user provides a subprogram which can contain any number of its own subroutines. The user subprogram is compiled separately and loaded with the appropriate TACO binary files to create a separate controllee.

User subprogram functions are handled in the same way as the piecewise linear functions of the prece.jing section. That is, positive curve numbers indicate time variations while negative signs on eurve numbers designate temperature variations. In order to distinguish a function provided by a user subprogram, a curve number greater tilan 999 (in absolute value) is assigned.

The details necessary for implementation of the user subprogram option are contained in Appendix A.

\subsection{PIIASE CHANGES}

A phase change can be approximated in TACO by defining a heat capacity curve with a discontinuity such as illustrated in the figure below. 


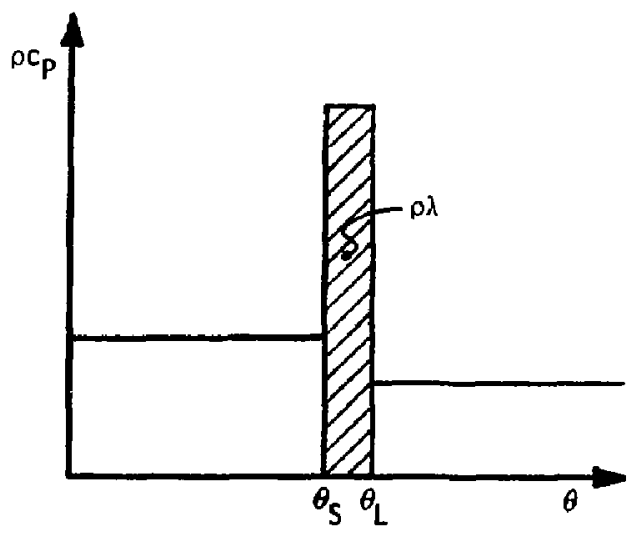

The cross-hatched rectangular area under the curve is equal to $\rho \lambda$ where $\rho$ is the density and $\lambda$ is the latent heat of the material. The width of the rectangular is given by $\theta_{\mathbf{L}}-\theta_{\mathbf{S}}$ where $\theta_{\mathbf{L}}$ is the liguidus temperature and $\theta_{\mathbf{S}}$ is the solidus temperature. Thus, the height of the rectangular is $\rho \lambda /\left(\theta_{L}-\theta_{S}\right)$.

For a material, such as a pure metal, where a phase change occurs at a unique temperature $\theta_{M}$ instead of over a temperature range bounded by $\theta_{S}$ and $\theta_{L}$, it is necessary to define fictitious values of $\theta_{\mathrm{S}}$ and $\theta_{\mathrm{L}}$ by

$$
\begin{aligned}
& \theta_{S}=\theta_{M}-\Delta \theta \\
& \theta_{L}=\theta_{M}+\Delta \theta
\end{aligned}
$$

where $\Delta \theta$ is some small temperature interval.

In TACO density and specific heat $c_{\mathrm{D}}$ are specified separately so that the ordinate of the $\rho c_{D}$ versus $\theta$ curve must he divided by $\rho$ to obtain the specific heat curve.

$-14-$ 
Care must he exereised in choosing the time step $\Delta$ for problems involving phase transformations. Several trials mav he required to determine a time step small enough to avoid missing the latent heat effect associated with the phase change (rectangular part of $\rho c_{p}$ curve ahovel. The variahle time step option mav he found useful in such prohlems.

\subsection{CHEMICAL KINETICS}

Calculations involving cluemical renctive kincties are handled in TACO through the usej subprogram option. Subprograms hnve becn developed for scveral types of reactive kinetics. These subprograms and instructions on their use may be obtained from the nuthor.

\subsection{UNITS}

Arv sei of units inay be used in TACO. However, all units must be consistent with the governing equations. An example of a consistent set of units is given in the table below.

\begin{tabular}{lll}
\multicolumn{1}{l}{ QUANTITY } & SYMBOL & $\underline{\text { Units }}$ \\
Temperature & 0 & ${ }^{\circ} \mathrm{C}$ \\
Spatial coordinate & $\mathrm{x}_{\mathrm{i}}$ & $\mathrm{in}$ \\
Time & $\mathrm{t}$ & $\mathrm{s}$ \\
Density & $\mathrm{o}$ & $\mathrm{kg} / \mathrm{m}^{3}$ \\
Specific heat & $\mathrm{c}_{\mathrm{p}}$ & $\mathrm{J} / \mathrm{kg} \cdot{ }^{\circ} \mathrm{C}$ \\
Thermal conductivity & $\mathrm{k}$ & $\mathrm{W} / \mathrm{m} \cdot{ }^{\circ} \mathrm{C}$ \\
Heat gentration rate & $\mathrm{Q}$ & $\mathrm{W} / \mathrm{m}^{3}$ \\
per unit volume & & $\mathrm{W} / \mathrm{m}^{2}$ \\
Heat flux per unit area & $\mathrm{q}$ &
\end{tabular}

(Note: The $\mathrm{kg}$ in the density represents kilogram mass). 
TACO has both fixed and variable time step capabilities. In addition, any number of fixed time step blocks may be specified allowing for variation of time step size in a stepwise fashion.

In order to insure accuracy, it is of ten necessary to make more than one run using different time step parameters. For example, if a fixed time step of $\Delta t$ were used, it may be advisable to make a second run with a time step of $\frac{1}{2} \Delta t$ and the solutions compared to see if the time step is small enough.

\subsection{STEADY STATE ANALYSIS}

As an implicit code, TACO can obtain a steady-state solution in one step. However, if the time to reach steady state is required, then a transient anaiysis must be performed.

Initial estimates for nocial temperatures in nor.]inear steady state problems may be input in place of initial conditions for transient problems.

\subsection{MESH GENERATION}

TACO has no general mesh generation of capability. Rows of evenly spaced nodes and rows of sequential elements may be generated, However, TACO relies on separate two-dimensional mesh generation codes (e.g., (4) and (ㅁ)) for complex zoning. The output from the mesh generation code is used to provide the nodal point and element data for TACO (see Sections 5.3 and 5.4). This data is then combined with the necessary acfitional data (Section 5) to construct the input decis or file for TACO. To avoid possible difficulties, the user is cautioned to request a complete ("long") list of nodal and element data when using a mesh generation code. 
The Gibbs-Poole-Stockmeyer algorithm ()ㅜ for determining a nodal numbering scheme to minimize the bandwidth and profile of the $K^{*}$ matrix is available as an option in TACO. The result of the selection of this option is essentially ransparent to the user. The or iginal and minimized bandwidth and profile data is printed. However, all nodal temporature data is written in terms of the user's original nodal numbering scheme.

\subsection{POST PROCESSING}

A comprnion post processor, POSTACO (1), is available for producing graphical output for data genersted by TACO. POSTACO reads the binary plot files produced by TACO and ean generate several types of plots. These include contour plots, nodal time history plots, and plots of temperature vs. distance along arbitrary cut lines.

\subsection{THERMAL STRESS ANALYSIS}

The temperatures calculated by TACO can be used in performing uncoupled thermal stress analyses with mechanical codes (e.g., (7)) These codes can read the temperature states from the binary plot files generated by TACO. 


\title{
3. A V AILABILITY
}

At Lawrence Livermore Laboratory TACO is available as a controllee on the OCTOPUS system. On the CDC 7600 computers, it resides in GLGLIB and can be obtained as follows:

\author{
EXE GLGLIB TACO DR. / $t$ v
}

On the CRAY computer, TACO is in MDGLIB and can be extracted with

LIB MDGLIB!X T'ACO!END / $\mathrm{t} v$ 


\title{
4. EXECUTION
}

TACO may be exeeuted directly from the teletype or indirectly through a batch processor.

The execution line is as follows:

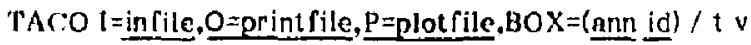

Here infile denotes the name given to the input fiJe deseribed in the User's Guide which follows. The name printfile is given to the BCD print file and plotfile denotes the root name of the familied binary plot file; produced by 'TACO. The entries ann and id are the user's box number ant output identifier. Entries infile, printfile. and plotfile are limited to six characters or less. 'The entries are order independent.

File name dropouts are permitted on the execution line. Some examples follow:

\author{
TACO I=infile, $, \underline{P=p l o t f i l e}, \mathrm{BOX}=(\underline{\mathrm{ann}}$ id) $/ \mathrm{t} \mathrm{v}$ \\ TACO P=plot îj]e. $1=$ infile, $\mathrm{O}=$ print file $/ \mathrm{t} v$ \\ TACO P=plotfi]e / $\mathrm{t} v$ \\ TACO $\mathrm{l}=$ infite, $B O X=($ ann $\underline{\text { id })} / \mathrm{t} v$
}

If infile is omitted, the name "TACOIN" is assumed. If print file is oritted, the print file name ".'PRINT" is used. Omission of plotfile results in the name "TPLOT" being assigned as the plot file root name. The "BOX=(ann id)" information mav be omitted unless execution is through a batch processor. 


\section{EXICCUTION (cont'd.)}

Plot files created by TACO are familied by appending a numeral starting with "01" to the root name plotfile. For example, if plotfile is "PLOT", the files will be familied as PLOT, PLOT01, PLOT02, PLOT03,...

Appendix C describes the plot file data base. 


\section{TACO USER'S GUIDE}

The following pages contain the instructions necessary to enable the user to construct the input file (data deck) required by TACO. In addition, a section (5.18) deseribes some interactive controls available to the user during interactive ezecution from a terminal.

\subsection{TITLE CARD}

Columns

$1-64$

Entry

Nole

8A8 Heading to appear on output

1

NOTE: 1. Any number of additional heading cards may be included. However, these additional cards must ha:e the character " $\&$ " in column 1.

Cards with the character " $\&$ " in column 1 can be placed anywhere in the data deck for use as comment cards or as spacers. All such cards are ignored by TACO.

If the word "STOP" is encountered in the first four columns, extution is terminated. Therefore, to be safe, the last card in the data should be a "STOP" eard. 


\section{Card 1}

\begin{tabular}{|c|c|c|c|c|}
\hline Columns & Format & & Er.try & Note \\
\hline $1-5$ & 15 & \multicolumn{3}{|c|}{ Number of nodal points. } \\
\hline $6-10$ & 15 & \multicolumn{3}{|c|}{ Number of elements. } \\
\hline $11-15$ & I5 & \multicolumn{3}{|c|}{ Number of materials. } \\
\hline $16-20$ & I5 & \multicolumn{2}{|c|}{$\begin{array}{l}\text { Number of elements with internal heat } \\
\text { generation. }\end{array}$} & 1 \\
\hline 21-25 & 15 & \multicolumn{2}{|c|}{$\begin{array}{l}\text { Number of nodes at which nonzero initial } \\
\text { temperatures are specified. }\end{array}$} & 2 \\
\hline $26-30$ & I5 & \multicolumn{2}{|c|}{$\begin{array}{l}\text { Number of nodes at which temperature } \\
\text { boundery conditions are specified. }\end{array}$} & 3 \\
\hline $31-35$ & I5 & \multicolumn{2}{|c|}{$\begin{array}{l}\text { Number of boundary segments on which } \\
\text { flux boundary conditions are specified. }\end{array}$} & 4 \\
\hline $36-40$ & 15 & \multicolumn{3}{|c|}{$\begin{array}{l}\text { Number of boundary segments on which } \\
\text { convection boundary conditions are specified. }\end{array}$} \\
\hline $41-45$ & 15 & \multicolumn{3}{|c|}{$\begin{array}{l}\text { Number of boundary segments on which nonlinear } \\
\text { boundary conditions are specified. }\end{array}$} \\
\hline $46-50$ & 15 & \multicolumn{3}{|c|}{ Number of special internal boundary elements. } \\
\hline $51-55$ & 15 & \multicolumn{3}{|c|}{ Number of bulk nodes. (See Section 5.13.) } \\
\hline $56-60$ & 15 & \multicolumn{3}{|c|}{$\begin{array}{l}\text { Number of boundary segments associatef with } \\
\text { bulk nodes. (See Sectior, 5.13.) }\end{array}$} \\
\hline $61-65$ & 15 & \multicolumn{3}{|c|}{$\begin{array}{l}\text { Number of segments involved with radiation in } \\
\text { enclosures. (See Section 5.14.) }\end{array}$} \\
\hline $66-70$ & I5 & \multicolumn{3}{|c|}{$\begin{array}{l}\text { Number of piecewise linear curves used to } \\
\text { describe time and/or temperature variations } \\
\text { of material properties, thermal loadings or } \\
\text { boundary conditions. }\end{array}$} \\
\hline \multirow[t]{4}{*}{$71-75$} & I5 & \multicolumn{3}{|c|}{ Data Cheek Code (IDATA) } \\
\hline & & IDATA = -1: & $\begin{array}{l}\text { normal execution without } \\
\text { printout of nodal point and element } \\
\text { input data }\end{array}$ & \\
\hline & & IDATA $=0$ : & $\begin{array}{l}\text { normal execution with complete } \\
\text { data printout }\end{array}$ & \\
\hline & & IDATA $=1:$ & data check only & \\
\hline $76-80$ & 15 & $\begin{array}{l}\text { Bandwidth and } \\
\text { IBAND = 0: } \\
\text { IBAND = 1: }\end{array}$ & $\begin{array}{l}\text { rofile Minimization Code (IBAND) } \\
\text { no minimization } \\
\text { minimization }\end{array}$ & \\
\hline
\end{tabular}




\section{CONTROL CARDS (cont'd.)}

NOTES: 1. Heat generation ates may he specified by element br by material isee Sections 5.5-5.61. However, the total number of elements must be given here.

2. Initial noda! temperatures iny be specified either on nodal coordinate cards or on separate cards (see Sections 5.3 and 3.7 ) or hoth. Two values given for the sume nore will be added. The number given here refers to those va!ues input ceparately ISection 5.7).

3. While referred to as temprrature "boundary conditions". any noda: temperature may be specified whether on a boundaly or not.

4. While referred to as "boundary segments". fluxes may he specified on any element boundal'y whether it is interior to the region or is, in fact, on the region boundary. 
CONTROL CARDS (cont'd.)

\section{Card 2}

Columns

$1-5$

6-10

$11-20$
Format

I5

Is

E10.0
Entry

Note

Type of geometry ([GEOM)

IGEOM = 0: axisymmetric

IGEOM = 1: plane

(DERAULT : IGEOM = 0)

Spatial Gaussian integration order (NGIO)

$I \leq \mathrm{NGIO} \leq 4$ (DEFAULT: NGIO $=2$ )

Scale factor for geometry XLENG

(DEFAULT: XLENG $=1.0$ ! 
CONTROL CARDS (cont'd.)

\section{Card 3}

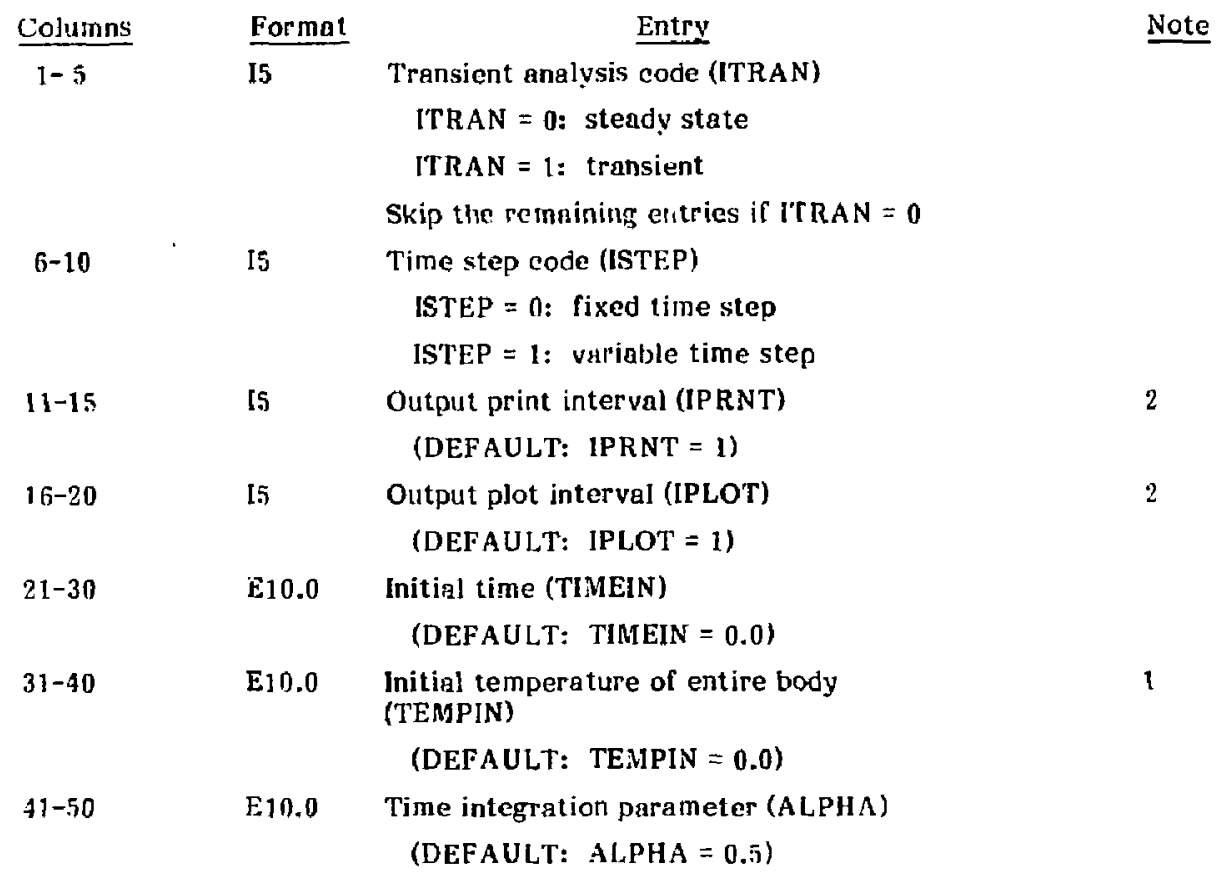

NOTES: 1. Initial temperatures may also be input as individual nodal values (see Sections 5.3 and 5.7). In such cases, the value given here (TEMPIN) will be assigned to all nodes except those whose initial temperatures are prescribed elsewhere. In nonlinear steady state prob!ems TEMPIN may be used as an initial temperature estimate for the iterative solution proeess.

2. The initial temperatures and the temperatures at the last time step will always be printed and plot ted unless printing or plotting is suppressed. Printing or plotting can be suppressed by setting either IPRNT or [PLOT respectively equal to a negative number.

3. The default of ALPHA $=0.5$ does not allow the time integration parameter to be set to exactly zero. If it is desired to set $A L P H A=0.0$, use a very small value (e.g., 1.0E-10) instead. 


\section{Card 4}

Skip if steady state solution (ITRAN $=0)$

Fixed Time Step (ISTEP=0)

\begin{tabular}{|c|c|c|c|}
\hline Columns & Format & Entry & Note \\
\hline $1-1.0$ & E10.0 & Time step size (DT) & \\
\hline $11-20$ & E 10.0 & Maximum time (TMAX) & 1 \\
\hline \multicolumn{4}{|c|}{ V ariable Time Step (ISTEP $=1$ ) } \\
\hline Columns & Format & Entry & Note \\
\hline $1-10$ & E10.0 & Initial time step (DT) & \\
\hline $11-20$ & E10.0 & Maximum Time (TMAX) & \\
\hline $21-30$ & E10.0 & $\begin{array}{l}\text { Minimum time step (DTMIN) } \\
\text { (DEFAULT: DTMIN }=1 . \mathrm{E}-10 \text { ) }\end{array}$ & 2 \\
\hline $31-40$ & E10.0 & $\begin{array}{l}\text { Maximum time step (DTMAX) } \\
\text { (DEFAULT: DTMAX }=1.5+10)\end{array}$ & 2 \\
\hline $4 t-50$ & E10.0 & $\begin{array}{l}\text { Maximum nodal temperature change below which } \\
\text { time step will be increased (DELMIN) } \\
\text { (DEFAULT: DELMIN }=1.0 \text { ) }\end{array}$ & 3 \\
\hline $51-60$ & E10.0 & $\begin{array}{l}\text { Maximum nodal temperature change above which } \\
\text { time step will be decreased (DELMAX) } \\
\text { (DEFAULT: DELMAX }=\mathbf{1 0 . 0} \text { ) }\end{array}$ & 3 \\
\hline $61-70$ & E10.0 & $\begin{array}{l}\text { Modification factor for decreasing time step } \\
\text { (DTDEC) (DT = DT } / D T D E C) \\
\text { (DEFAULT: DTDEC }=2.0 \text { ) }\end{array}$ & \\
\hline $71-80$ & E10.0 & $\begin{array}{l}\text { Modification factor for increasing time step } \\
\text { (DTINC) (DT = DT*DTINC) } \\
\text { (DEFAUI,T: DTINC }=\mathbf{2 . 0} \text { ) }\end{array}$ & \\
\hline
\end{tabular}


CONTROL CARDS (cont'd.)

NOTES: 1. A fixed time step size may be changed during cxecution with the NEWSTEP option deseribed in Seetion 5.16 .

2. A calculated time step of less than the minimum step size (DTMIN) will result in a termination of execution. A calculated time step of greater than the inaximum step size (DFMAX) will be replaced ty UTMAX.

3. At each time step, the node at which the maximum temperature change (in absolute value) oceurs will be determined. If the maximum temperature change is less than DELMTN, the time step will be inereased. If the maximum temperature change is greater than DELMAX. the step size will be decreased and the time step started over. 
CONTROL CARDS (cont'd.)

\section{Card 5}

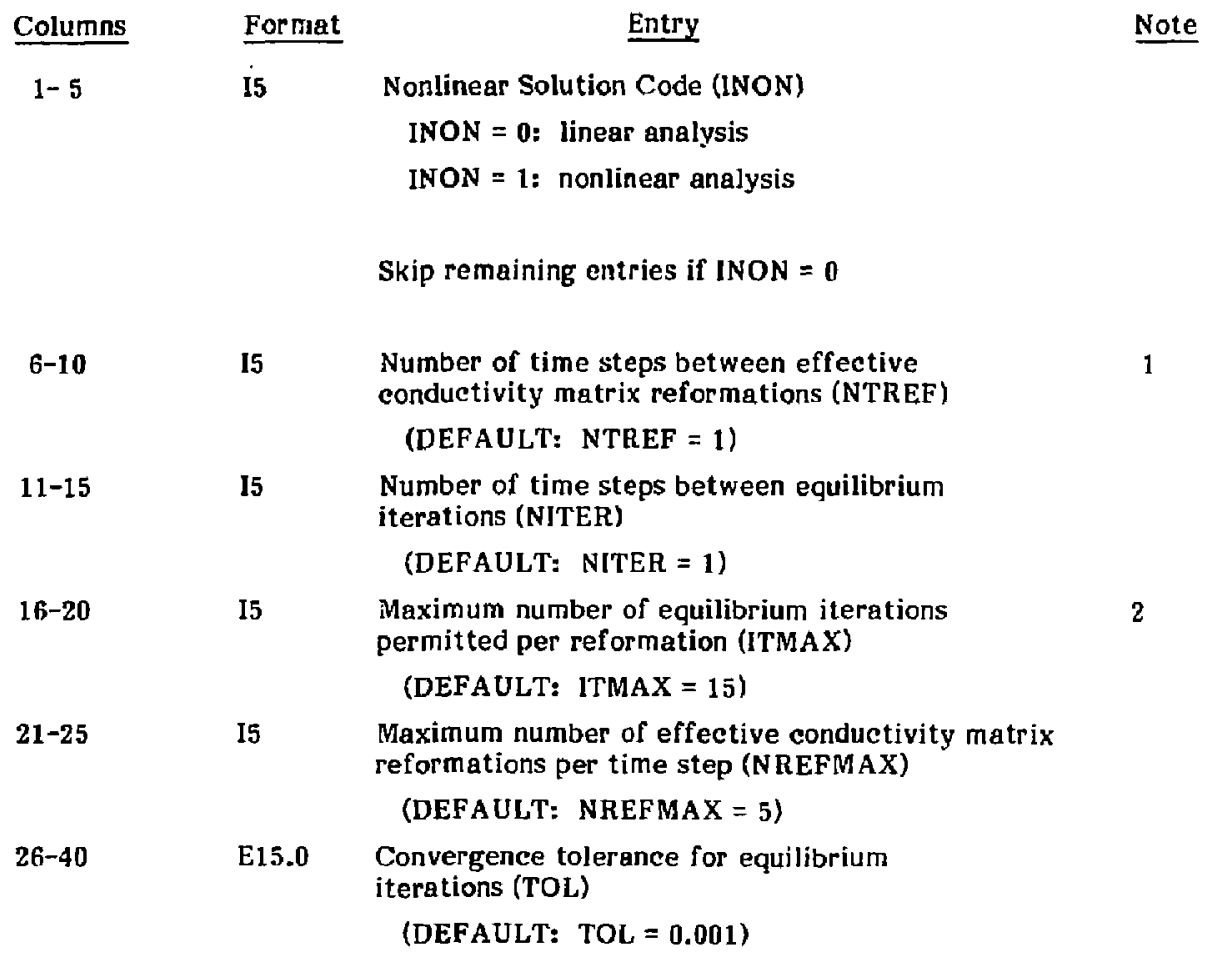

NOTES: 1. If the time step changes, a reformation is made regardless of the value of NTREF.

2. If no reformation is made within a time step, ITMAX is the maximum number of iterations permitted within the time step. For nonlinear, steady-state problems, the default value is ITMAX $=1$. 
CONTROI, CARDS (cont'd.)

\section{Card 6}

Columns

$1-5$
Format

15

Entry

Note

Temperature unit code (IUNITS)

IUNITS $=0$ : dimensionless

IUNITS $=1$ : Centigrade

IUNITS $=$ 2: Kelvin

IUNITS $=3:$ Fabrenheit

IUNITS $=4:$ Rankine 


\subsection{NODAL POINT DATA}

\begin{tabular}{clll} 
Columns & Format & Entry \\
\cline { 1 - 1 } $1-5$ & I5 & Node point number \\
$6-10$ & $5 X$ & Skip \\
$11-20$ & E10.0 & x-or r-coordinate \\
$21-30$ & E10.0 & y-or z-coordinate \\
$31-40$ & E10.0 & Initial temperature \\
$41-45$ & I5 & Generation itrerement (INC) \\
& & (DEFAULT: INC $=0)$
\end{tabular}

NOTES: 1. Node point cords need not be in order. However, the highest node number must terminate the datn. When data is missing, node numbers are generated according to the sequence

$$
N_{i}, N_{i}+I N C, N_{i}+2 * I N C, \ldots, N_{j}
$$

where $\mathrm{N}_{\mathrm{i}}$ and $\mathrm{N}_{\mathrm{j}}$ are the node numbers on two consecutive cards and INC is read from the $N_{j}$ card. Linear interpolation is used to calculate the coordinates of the generated nodes. If INC is zero or blank, no nodes are gencrated.

3. Any non-zero values read here will replace those nodal temperatures assigned the value TEMPIN in Section 5.2 (Card 3). Initial nodal temperatures may also be input separately in Section 5.7. Initial temperatures may be used as initial estimates for iterative solutions of nonlinear steady state problems. 


\section{I.4 ELEMENT DATA}

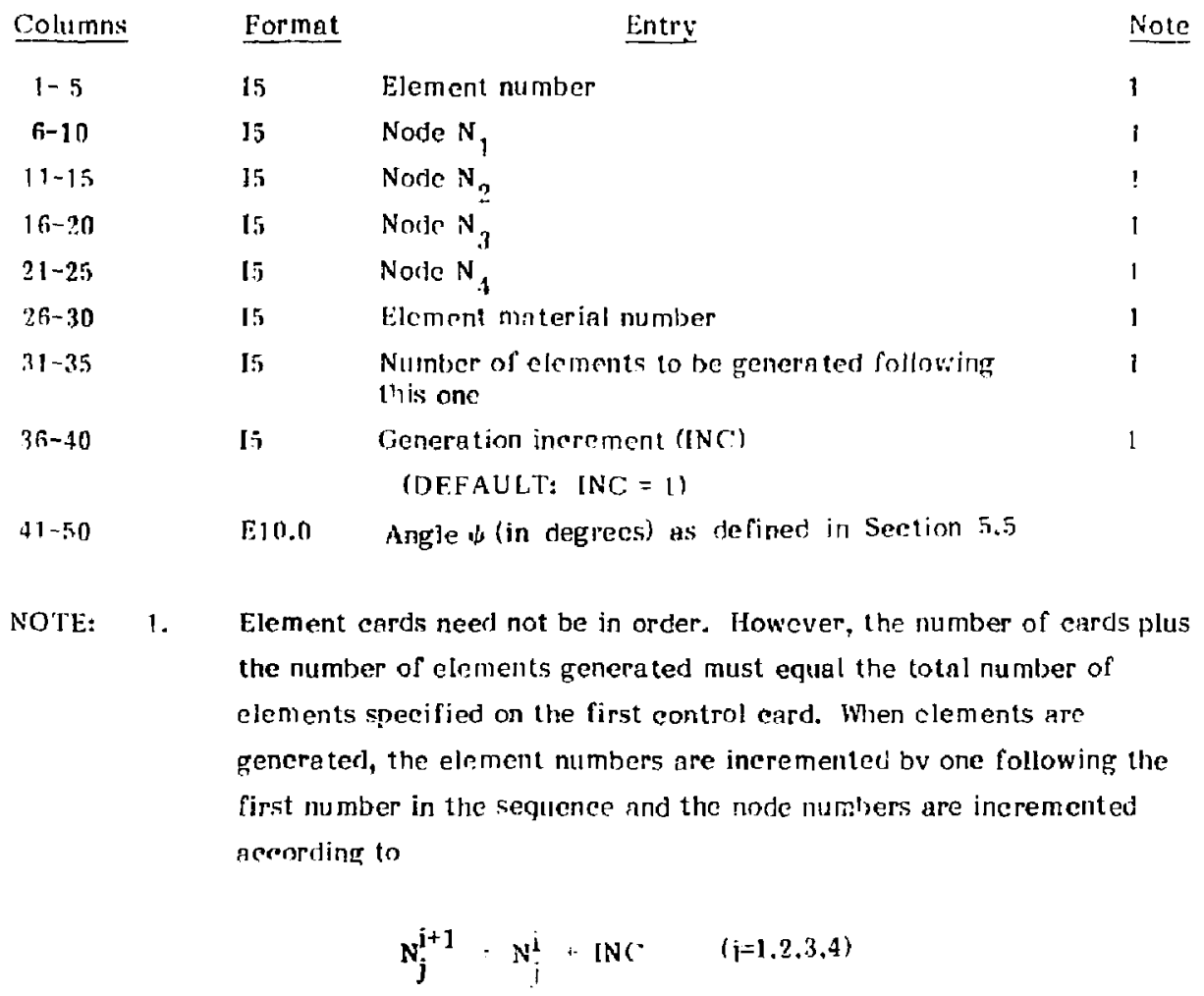

Element node numbers $\mathrm{N}_{1}-\mathrm{N}_{4}$ can begin at any one of the four nodes but must be numbered counterelockwise around an element: 


\subsection{MATERIAL PROPERTY DATA}

\section{Card 1}

\begin{tabular}{|c|c|c|c|}
\hline Columns & Format & Entry & Note \\
\hline $1-10$ & A10 & Material identification & \\
\hline $11-15$ & I5 & Material identification number & 1 \\
\hline $16-20$ & 15 & $\begin{array}{l}\text { Material type (MTYPE) } \\
\text { MTYPE = 0: null material } \\
\text { MTYPE = 1: isotropic } \\
\text { MTYPE }=2: \text { globally orthotropic } \\
\text { MTYPE }=3: \text { locally orthotropic }\end{array}$ & 2,3 \\
\hline $21-30$ & E10.0 & Density $\rho$ & \\
\hline $31-35$ & 15 & Curve number for specific heat $c_{p}$ & 4 \\
\hline $36-50$ & E15.0 & Specific hent if eurve number is zero & \\
\hline $51-55$ & I5 & Curve number for heat generation rate $Q$ & 4 \\
\hline $56-70$ & E15.0 & $\begin{array}{l}\text { Curve multiplier for heat generation rate } \mathbf{Q} \\
\qquad \text { Card 2 }\end{array}$ & \\
\hline \multicolumn{4}{|c|}{ Material Type 1 (Isotropic) } \\
\hline Columns & Format & Entry & Note \\
\hline $1-5$ & I5 & Curve number for thermal conductivity $k$ & 4 \\
\hline $6-20$ & E15.0 & Thermal conductivity $k$ if curve number is zero & \\
\hline
\end{tabular}




\section{Card 2 (cont'd.)}

Material Types 2 and 3 (Orthotropic)

\begin{tabular}{|c|c|c|c|}
\hline Columns & Format & Entry & Not \\
\hline $1-5$ & 15 & Curve number for thermal conduetivity $k_{1}$ & 4 \\
\hline $6-20$ & E15.n & $\begin{array}{l}\text { Thermal conductivity } k_{1} \text { : enrve number } \\
\text { is zero }\end{array}$ & \\
\hline $21-25$ & 15 & Curve number for thermal conduetivity $\mathrm{k}_{2}$ & 4 \\
\hline $26-40$ & E15.n & $\begin{array}{l}\text { Thermal conductivity } k_{2} \text { if curve ni wher } \\
\text { is zero }\end{array}$ & \\
\hline $41-50$ & E10.0 & $\begin{array}{l}\text { Global material angle } \psi_{\mathrm{G}} \text { (in degrees) } \\
\text { if material type } 2\end{array}$ & 3 \\
\hline
\end{tabular}

NOTES: 1. The material identification numbers must be less than or equal to the number (NUMNAT) given on the first control card (Section 5.2). The total number of materials identified must equal NUMMAT.

2. If MTYPF $=0$, any elements with the corresponding material identification number will be deleted.

3. Material orthotropy may be specified either globally or locally. In the case of a global definition, a global material angle is defined as in the following figure where $x_{1}$ and $x_{2}$ denote the material axes:

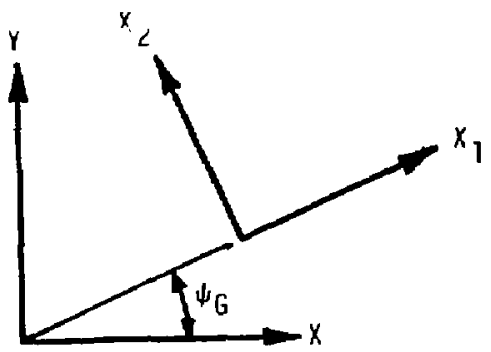




\section{Card 2 (cont'd.)}

For the case of locallv specified material orthotropy, an angle $\psi$ is tefined for each element as follows

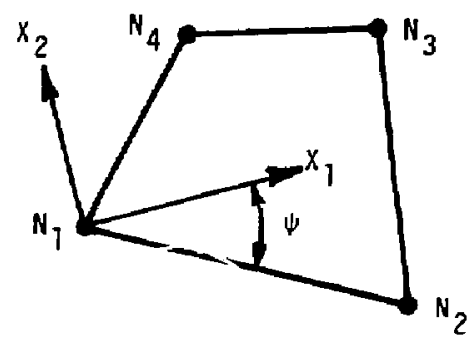

The individual angles $\psi$ reare innut in the element definitions Section 5.41.

4. Time dependent, temperature dependent, and constant functional relations are indicated by positive, negative, and zero curve numbers respectively.

Curve numbers greater than 999 in absolute value indicate that a user subroutine is being provided to evaluate particular functions. 


\subsection{HEAT GENERATION DATA}

\begin{tabular}{|c|c|c|c|}
\hline Columns & Format & Entry & Note \\
\hline $1-5$ & I5 & Element number & 1,2 \\
\hline $6-10$ & I5 & Curve number for heat generation rate $Q$ & 3 \\
\hline $11-20$ & E10.0 & Cur ve mitiplier for $Q$ & 4 \\
\hline $21-25$ & I5 & $\begin{array}{l}\text { Number of elements to be generated following } \\
\text { this che }\end{array}$ & 1 \\
\hline $26-30$ & Is & $\begin{array}{l}\text { Generntion jnerement (INC) } \\
\text { (DEFAULT: INC }=1 \text { ) }\end{array}$ & 1 \\
\hline
\end{tabular}

NOTES: 1. Hent generation cards need not be in order. When elements are Fenerated, the element numbers are ineremented by INC as in the case of element eards (Seetion 5.4). The number of cards plus the number generated must equal the total number specified on the first control eard. rurve numbers and mu.tipliers are set to the the same value for ench clement in the sequence.

2. Heat generation may also be specified by material (see Section 5.5). If an element has heat generation specified both by element and by materjal, the effeet will be additive.

3. A curve number with a positive sign indicates time dependent heat gencration. A curve number with a negative sign indieates that the heat generation is temperature dependent. A curve number of zero indicates constant heat generation rate.

A curve number of greater than 999 indicates a user subroutine is used to provide heat generation rates. The positive and negative signs is used, as above, to indicate time or temperature variation.

4. If a curve number of zero is given, the curve muitiplier then becomes the constant heat $E$ ieration rate. 


\subsection{INITIAL TEMPERATURE DATA}

\begin{tabular}{|c|c|c|c|}
\hline Columns & Formet & Entry & Note \\
\hline $1-5$ & 15 & Norle number & 1 \\
\hline $6-20$ & E15.0 & Initial temperature & 2 \\
\hline $21-25$ & 15 & $\begin{array}{l}\text { Number of nodes to be generated following this } \\
\text { one (NMISS) }\end{array}$ & 1 \\
\hline $26-30$ & 15 & $\begin{array}{l}\text { Generation increment (INC) } \\
\text { (DEFAULT: INC }=1 \text { ) }\end{array}$ & 1 \\
\hline
\end{tabular}

NOTES: 1. Initial temperature eards need not be in order. When data is generated, node numbers are incremented according to the sequence

$$
N_{i}, N_{i}+I N C, N_{i}+2 * I N C, \ldots, N_{i}+N M I S S * I N C
$$

The number of cầds in this section plus the number generated must equal the number indicated on the first control card (Section 5.2).

2. Initial notial temperatures may also be input in Section 5.3. Values of initial nodal temperature given in this section will replace any previouslspecified values. 
5.8 NODAL TEMIPERATURE SPECIFICATION

\begin{tabular}{|c|c|c|c|}
\hline Columns & Format & Eniry & Note \\
\hline $1-5$ & 15 & Node number & 1 \\
\hline $6-10$ & 15 & Time function curve number & 2 \\
\hline $11-20$ & E.10.n & Curve multiplier & 2 \\
\hline $21-25$ & 15 & $\begin{array}{l}\text { Number of nodes to be generated following } \\
\text { this one (NMISS) }\end{array}$ & 1 \\
\hline $26-30$ & I5 & $\begin{array}{l}\text { Generation inerement (INC) } \\
\text { (DEFAULT: INC = I) }\end{array}$ & 1 \\
\hline
\end{tabular}

NOTES: 1. Nodal temperature specification cards need not be in order. When data is generated, node numbers are incremented according to the sequence

$$
\mathrm{N}_{i}, \mathrm{~N}_{\mathrm{i}}+\left[\mathrm{NC}, \mathrm{N}_{\mathrm{i}}+2 * I \mathrm{NC}, \ldots, \mathrm{N}_{\mathrm{i}}+\mathrm{N}_{\mathrm{M}} \mathrm{MISS} * 1 \mathrm{NC}\right.
$$

The number of cards in this section plus the number generated mus1 equal athe number indicated on the first control card (Section 5.2).

2. In order to specify a constant value of nodal temperature, set the curve number to zero and the multiplier to the desired value. 


\subsection{FLUX BOUNDARY CONDITION DATA}

\begin{tabular}{|c|c|c|c|}
\hline Columns & Format & Entry & Note \\
\hline $1-5$ & 15 & Node $\mathbf{N}_{\mathbf{i}}$ & 1 \\
\hline $6-10$ & I5 & Node $\mathrm{N}_{2}$ & 1 \\
\hline $11-15$ & $5 \mathbf{x}$ & Skip & \\
\hline $16-20$ & 15 & Curve number for flux & 3 \\
\hline $21-30$ & E10.0 & Curve multiplier at node $\mathrm{N}_{\mathrm{t}}$ & 2,4 \\
\hline $3 t-40$ & E10.0 & Curve multiplier at node $\mathrm{N}_{2}$ & 2,4 \\
\hline $41-45$ & 15 & $\begin{array}{l}\text { Number of segments to be generated following } \\
\text { this one }\end{array}$ & 1 \\
\hline $46-50$ & $\mathbf{I 5}$ & $\begin{array}{l}\text { Generation increment (INC) } \\
\text { (DEFAULT: INC }=1 \text { ) }\end{array}$ & 1 \\
\hline
\end{tabular}

NOTES: 1. Flux boundary condition segment cards need not be any numerical order. When segments are generated, the node numbers will be incremented according to

$$
v_{i}^{i+1} \quad N_{j}^{i}+\operatorname{INC}(j=1,2)
$$

The number of cards in this section plus the number of segments generated must equal the number given on the first control card (Section 5.2).

2. Flux on a bcundary segment is allowed to vary in a linear fashion as shown below.

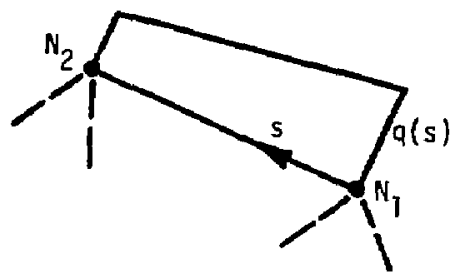


FIUX BOUNDARY CONDITION DATA (cont'd.)

NOTFS: 3. A positive cusve number indieates a time dependent flux. A rurve number preceder by a negative sign indieates a temperature dependent flux. A curve number of zero indicates a const ant flux.

A curve number of greater than 999 indicates a user subroutine is provided for flux values. The positive and negative sign is used, as sbave, to indieate time or temperature variation.

4. If a curve number is zero, the curve multipliers then become the constant segment and point flux values. 


\subsection{CONVECTION BOUNDARY CONDITION DATA}

\begin{tabular}{|c|c|c|c|}
\hline Columns & Format & Entry & Note \\
\hline $1-5$ & [.5 & Node $N_{1}$ & 1 \\
\hline $6-10$ & I5) & Node $\mathrm{N}_{2}$ & 1 \\
\hline $11-15$ & $5 X$ & Skip & \\
\hline $16-20$ & 15 & $\begin{array}{l}\text { Function eurve number for heet transfer } \\
\text { coefficient } h\end{array}$ & 2 \\
\hline $21-30$ & E10.0 & Curve multiplier for $h$ & 3 \\
\hline $31-35$ & $5 \mathbf{x}$ & Skip & \\
\hline $36-40$ & is & $\begin{array}{l}\text { Time function curve number for convective } \\
\text { equilibrium tempernture } \theta_{\infty}\end{array}$ & 2 \\
\hline $41-50$ & E10.0 & Curve mu'tiplier for $\theta_{\infty}$ at node $N_{1}$ & 3.4 \\
\hline $51-60$ & E10.0 & Curve inultiplier for $\theta_{\infty}$ at node $\mathrm{N}_{2}$ & 3.4 \\
\hline $61-65$ & 15 & $\begin{array}{l}\text { Number of segments to be generated } \\
\text { following this one }\end{array}$ & 1 \\
\hline $66-70$ & I5 & $\begin{array}{l}\text { Generation increment (INC) } \\
\text { (DEFAULT: INC }=1 \text { ) }\end{array}$ & 1 \\
\hline
\end{tabular}

NOTES: 1. Convection boundary condition segment eards need not be in any numerical order. When segments are generated, the node numbers will be ineremented according to

$$
N_{j}^{i+1}=N_{j}^{i}+\operatorname{INC}(j=1,2)
$$

The number of eards in this section must equal the number given on the first control eard (Section 5.2?.

2. Time dependent, temperature dependent, and constant functional relations are indicated by positive, negative and zero curve numbers respectively. 
CONVEC'TION BOUNDARY CONDITION DATA (cont'd.)

Curve numbers grenter than 999 in ahsolute value indicate that it user subroutine is heing provided to evaluate particular funetions.

Convective equilibrium temperatures should be either functions of time or constants (i.e., curve numbers should not he negative).

3. If a curve number is zero, the curve multipliers then becone the constnnt values heing specified for the function.

4. Sonvective equilibriam tempnratures are allowed to vary in a linear fashion along a segment by specifying separate values at each $\mathrm{md}$ of the segment. 


\subsection{GENERAL NONLINEAR BOUNDARY CONDITION DATA}

\section{Card 1}

\begin{tabular}{|c|c|c|c|}
\hline Columns & Format & $\underline{\text { Entry }}$ & Note \\
\hline $1-5$ & I5 & Node $N_{1}$ & 2 \\
\hline $6-10$ & I5 & Node $\mathrm{N}_{2}$ & 2 \\
\hline $11-15$ & $5 \mathbf{x}$ & Skip & \\
\hline $16-20$ & I5 & Function curve number for coefficient $f$ & 3 \\
\hline $21-30$ & E10.0 & Curve multiplier for $f$ & 4 \\
\hline $31-35$ & $5 x$ & Skip & \\
\hline $36-40$ & I5 & $\begin{array}{l}\text { Time function eurve number for equilibrium } \\
\text { temperature } \theta_{\infty}\end{array}$ & 3 \\
\hline $41-50$ & E10.0 & Curve multiplier for $\theta_{\infty}$ at node $\mathrm{N}_{1}$ & 4 \\
\hline $51-60$ & E10.0 & Curve mu'tiplier for $\theta_{\infty}$ at node $\mathrm{N}_{2}$ & 4 \\
\hline $61-70$ & E10.0 & Exponent "a" & 1 \\
\hline $71-80$ & E10.0 & Exponent "b" & 1 \\
\hline
\end{tabular}

\section{Card 2}

\begin{tabular}{|c|c|c|c|}
\hline Columns & Format & Entry & No:e \\
\hline $1-5$ & 15 & $\begin{array}{l}\text { Number of segments to be generated rollowing } \\
\text { this one }\end{array}$ & 2 \\
\hline $6-10$ & I5 & $\begin{array}{l}\text { Generation inerement (INC) } \\
\text { (DEFAULT: INC }=1 \text { ) }\end{array}$ & 2 \\
\hline
\end{tabular}

NOTES: t. General nonlinear houndary conditions are of the form

$$
\mathrm{q}=\mathrm{f}(\theta, t)\left[\theta^{\mathrm{a}}-\theta_{\infty}^{\mathrm{a}}(\mathrm{t})\right]^{\mathrm{b}}
$$

(Sce Section 2.10 for a detailed discussion.) 


\section{GENER AL, NONJINEAR BOUNDARY CONIDITION IOATA (cont'A.)}

2. Boundary seginent cards need not be in any nttmerienl order. When sngments are generated. the nodo numbers will be inerrmented necorting to

$$
N_{j}^{i+l} \quad N \quad+\operatorname{INC}(j \cdot 1,2)
$$

The number of segment cards read in this section plus the number generated must equal the number given on the first control card (Sectirn 5.2 ),

3. Time dependent, temperature dependent, gnd eonstant funetions! relgtions are indicated by positive. negative and zero curve number: respectively.

Curve numbers greater than 999 in absolute value indicate that a user subroutine is being provided to evaluate perticular functions.

Equilibriam temperatures should be either functions of time or constants (curve numbers shoulo not he negative).

4. If a curve number is zero, the curve mu'tiplier's then become the constant values being specified for the function.

Equilibrium tempratures are allowed to vary in a linear fashion along a segment by specifying separate values at ench end of the segment. 


\subsection{INTERNAL SURFACE CONDITION DATA}

\begin{tabular}{|c|c|c|c|}
\hline Columns & Format & Entry & Note \\
\hline $1-5$ & I5 & Node $\mathbf{N}_{1}$ & 1,2 \\
\hline $6-10$ & I5 & Node $\mathbf{N}_{2}$ & 1,2 \\
\hline $11-15$ & 15 & Node $\mathrm{N}_{3}$ & 1,2 \\
\hline $16-20$ & I5 & Node $\mathrm{N}_{4}$ & 1,2 \\
\hline $21-25$ & $5 x$ & Skip & \\
\hline $26-30$ & I5 & Curve number for coefficient $\mathfrak{f}$ & 3 \\
\hline $31-40$ & E10.0 & Curve multiplier for $f$ & 4 \\
\hline 41-50 & E10.0 & Exponent "a" & 1 \\
\hline $51-60$ & $\mathrm{E} 10.0$ & Exponent "b" & 1 \\
\hline $61-65$ & 15 & $\begin{array}{l}\text { Number of segments to be generated } \\
\text { following this one }\end{array}$ & 2 \\
\hline $66-70$ & 15 & $\begin{array}{l}\text { Generation increment (INC) } \\
\text { (DEFAULT: INC = 1) }\end{array}$ & 2 \\
\hline
\end{tabular}

NOTES: $1 . \quad$ Internal surface conditions are of the form

$$
\mathrm{q}=\mathrm{f}(\theta, \mathrm{t}) \quad\left[\begin{array}{ll}
\theta_{\mathrm{A}}^{\mathrm{a}} & -\theta_{\mathrm{B}}^{\mathrm{a}}
\end{array}\right]^{\mathrm{b}}
$$

Four nodes are required to define an internal surface condition. These nodes should be numbered as shown in the following figure:

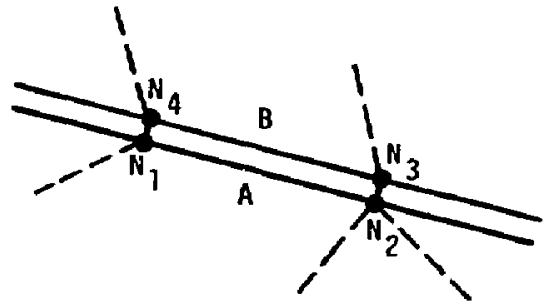


INTERNAL BOUNDARY CONDITION DATA (cont'd.)

Surface "A" should be defined by nodes $N_{1}$ and $N_{2}$ and surface " $B$ " by nodes $\mathrm{N}_{3}$ and $\mathrm{N}_{4}$. No two node numbers may be the same.

However, nodes $\mathrm{N}_{1}$ and $\mathrm{N}_{4}$ can have the same coordinates.

likewise for $N_{2}$ and $N_{3}$.

2. These eards need not be in any numerieal order. However, the Iumber of eurds plus the number of elements generated must equal the lofal number of elements specified on the first control card. When alements are generater, the element numbers are inerementerf by one following the first number in the sequence and the rode numbers are ineremented aceording to

$$
v_{i}^{i+1} \cdot N_{j}^{i}+\text { INC }(j=1.2,3.4)
$$

3. Time dependent, temperature dependent, and constant functional relations are indicated by positive, negative, and zero curve numbers respectively.

Curve numb' s greater than 999 in absolute value indicate that a user subroutine is being provided to evaluate particular functions.

4. If a curve number is zero, the curve multipliers then becorne the constant values being specified for the function. 


\subsection{BULK NODE DATA}

\section{Card 1}

\begin{tabular}{|c|c|c|c|}
\hline Columns & Format & Entry & Note \\
\hline $1-5$ & 15 & Bulk node number & 1 \\
\hline $6-10$ & 15 & Material number of bulk node & 1 \\
\hline $11-15$ & 15 & $\begin{array}{l}\text { Number of boundary segments associated } \\
\text { with this bulk node (NBNSEG) }\end{array}$ & 2 \\
\hline $16-30$ & E15.0 & Total volume associated with this bulk node & 1 \\
\hline NO'TES: & \multicolumn{3}{|c|}{$\begin{array}{l}\text { The number of bulk nodes input must be equal to the number } \\
\text { indicated on the first control card (Section 5.2). Each bulk node } \\
\text { must be assigned a material number. This allows the density and } \\
\text { specify heat for the material represented by a bulk node to he } \\
\text { input in Section } 5.5 \text {. The total volume of material represented by } \\
\text { each bulk node is required to be input also. }\end{array}$} \\
\hline
\end{tabular}

2. The number of element boundary sigments (NBNSEG), associated with each bulk node must be given. The total number of segments for all of the bulk nodes must equal the number indicated on the first control card (Section 5.2). A lumped heat capacity for a node may be specified by identifying a bulk nore with no associnter boundary segments $($ NBNSEG $=0)$. 


\section{Card 2}

Omit if NBNSEG $=0$.

\begin{tabular}{|c|c|c|c|}
\hline Columns & Trmat & Entry & Note \\
\hline $1-5$ & {$[\overline{7}$} & Node $N_{1}$ & 2 \\
\hline $6-10$ & 15 & Node $\mathrm{N}_{2}$ & $?$ \\
\hline $11-1 ;$ & $5 x$ & Skip & \\
\hline $16-20$ & I.5 & Curve number for coefficient $f$ & 3 \\
\hline $21-30$ & E10.0 & Curve multiplier for $f$ & 4 \\
\hline $31-40$ & E10.0 & Exponent "a" & 1 \\
\hline $41-50$ & E10.0 & Exponent "b" & 1 \\
\hline $51-55$ & 15 & $\begin{array}{l}\text { Number of segments to be generated } \\
\text { following this one }\end{array}$ & 2 \\
\hline $36-60$ & 15 & $\begin{array}{l}\text { Generation inerement }(\text { INC }) \\
\qquad([E E A U L T: \quad \text { INC }=1)\end{array}$ & 2 \\
\hline
\end{tabular}

NOTES: 1. The heat flow equntion for a bulk node is of the form

$$
\mathrm{q}=\mathrm{f}(\boldsymbol{\theta} \cdot \mathrm{t}) \quad\left[\theta_{\mathrm{S}}^{\mathrm{a}}-\theta_{\mathrm{B}}^{\mathrm{a}}\right]^{\mathrm{b}}
$$

(See Section 2.14 for a detailed discussion.)

2. These cards need not be in any numerical order. When segments are genergted, the element numbers are incremented by one following the first number in the sequence and the node numbers are incremented according to

$$
\mathrm{N}_{\mathrm{j}}^{\mathrm{i}+1} \div \mathrm{N}_{\mathrm{j}}^{\mathrm{i}}+\text { INC }(\mathrm{j}=1,2)
$$

3. Time dependent, temperature dependent, and constant functional relations are indicated bv positive, negative, and zero curve numbers respectively. 
BUIJK NODE DATA (cont'd.)

Curve numbers greater than 999 in absolute value indicate that a user subroutine is being provided to evaluate particular functions.

4. If a curve number is zero, the curve mu'tipliers then become the constant values being specified for the function. 


\section{Card 1}

\begin{tabular}{|c|c|c|c|}
\hline Columns & Format & Entry & Note \\
\hline $1-5$ & I5 & Seginent number & 1,2 \\
\hline $6-10$ & I5 & Nod. $\mathrm{N}_{1}$ & 1,2 \\
\hline $11-15$ & IS & Nodr $\mathrm{N}_{2}$ & 1,2 \\
\hline $16-20$ & 15 & Curse number for emissivity & 3 \\
\hline $21-30$ & E10.0 & Curve multiplier for emissivity & 4 \\
\hline $31-35$ & 15 & $\begin{array}{l}\text { KFLAG, flag indicating whether segment } \\
\text { participates in conduction part of problem, } \\
\text { K. LAG = 1, segment participates } \\
\text { KFLAG = 1, no participation }\end{array}$ & 5 \\
\hline $36-40$ & 15 & $\begin{array}{l}\text { Nuss per of segments to be generated } \\
\text { following this one }\end{array}$ & 1 \\
\hline $41-45$ & I5 & $\begin{array}{l}\text { Generation increment (INC) } \\
\text { (DFFAULT: INC }=1)\end{array}$ & 1 \\
\hline
\end{tabular}

NOTES: 1. The number of segments participating in enelosure radiation which are input must be efual to the number indicated on the firs, control card. Segments must have a number assigned to them such as shown in the example below.

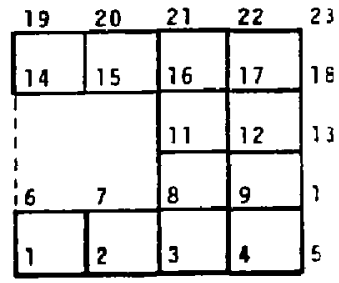

\begin{tabular}{|ccc|}
\hline Segment No. Node $\mathrm{N}_{2}$ & Node $\mathrm{N}_{2}$ \\
\hline 1 & 7 & 6 \\
2 & 8 & 7 \\
3 & 11 & 8 \\
4 & 16 & 11 \\
5 & 15 & 16 \\
6 & 14 & 15 \\
7 & 6 & 14 \\
\hline
\end{tabular}




\subsection{ENCLOSURE RADIATION DATA (cont'd.)}

2. Segment eards need not be in order. When segments are generated, the segment numbers are ineremented by one following the first number in the sequence and tie node numbers are incremented according to

$$
N_{i}^{\prime+1} \cdot N_{I} \cdot 1 N C(j=1,2)
$$

Segment code number must be ordered in the clockwise direction around the enclosure (see above figure).

3. Time dependent, temperature dependent, and constant functional relations are indicated by positive, negative, ano zero curve numbers respectively.

Curve numbers greater than 999 in absolute value indicate that a user subroutine is being provided to evaluate particular functions.

4. If a curve number is zero, the curve multipliers then become the constant values being specified for the function.

5. It is often necessary to set the temperature of a segment $\theta_{k}$ equal to a fixed value and the emissivity $\varepsilon_{k}=1.0$. Such would be the case of Segment No. 7 in the figure for Note 1 where the segment is used to represent the opening of a cavity to an external radiative environment of a fixed temperature. In order to accomplish this within TACO, the eurve multiplier for emissivity is given a value equal to the negative of the desired temperature.

6. Segments which only participate in the radiation part of the problem and not, directly, in the conduction part should be indicated by setting KFLAG $=1$. Segment No. 7 illustrated in the figure with Note 1 is such a segment. Segments with KFLAG $=1$ will be indicated in the printout by $a^{\text {"I*r" }}$ appended to the segment number. 


\section{Card 2}

\begin{tabular}{|c|c|c|c|}
\hline Columns & Format & Entry & Note \\
\hline \multirow{2}{*}{$1-5$} & 15 & Symmetry code (ISY $M$ ) & \\
\hline & & $\begin{array}{l}\text { ISYM=0: no symmetry } \\
\text { ISYM=1: symmetry about } x \text {-or } r \text {-axis } \\
\text { ISYM=2: symmetry about } y \text {-axis } \\
\text { ISYM=3: symmetry about both axes }\end{array}$ & \\
\hline \multirow[t]{2}{*}{$6-10$} & I5 & Code for view factors (N VIEW) & \\
\hline & & $\begin{array}{l}\text { NVIEWV=0: view fectors are calculated } \\
\text { NVIEWf 0: NVIEh view factors are read }\end{array}$ & \\
\hline $11-20$ & E10.0 & Stefan-Boltzmann constant & \\
\hline $21-25$ & 15 & $\begin{array}{l}\text { Number of divisions per segment in view } \\
\text { faetor ealeulations (NDIV), (DEF AULT: NDIV=10) }\end{array}$ & 1 \\
\hline \multirow[t]{2}{*}{$26-30$} & 15 & View faetor print flrg (IVP) & \\
\hline & & $\begin{array}{l}\text { IV } P=0 \text { : view facto:s not printed } \\
\text { IV } P=1 \text { : view factors printed }\end{array}$ & \\
\hline \multirow[t]{4}{*}{$.31-35$} & I5 & View ractor file flag (IV FILE) & \\
\hline & & $\begin{array}{ll}\text { IVFILE= } 1: & \text { vie } w \text { faetors written into BCD file } \\
\text { namec "VIElus" }\end{array}$ & \\
\hline & & IV FILE $=0$ : view factors not written & \\
\hline & & $\begin{array}{ll}\text { IVFILE }=-1: & \begin{array}{l}\text { view factors are read from file } \\
\text { named "VIEWS" }\end{array}\end{array}$ & \\
\hline
\end{tabular}

NOTES: 1. The larger the value of NDIV, the more computer time will be required to calculate the view factors. If no segments are partially obstructed from the view of any other segments, NDIV = 1 will give accurate values for view factors. If partial obstructions exist, the larger the value of NDIV, the more accurate the ealculated view factors will be. 


\subsection{ENCLOSURE RADIATION DATA (cont'd.)}

\section{Card 3}

Skip if $N$ VIEW=0 or IV FILE=-1

Columns

1-5

6-10

11-20

\section{Format}

I5

I5

E10.0

\section{Entry}

Number of segment $k$

Number of segment $j$

View factor $F_{k-j}$
Note

1

1

1

NOTES: 1. Cards defining view factors for all surfaces to be included in the radiation calculations must be input (Total $=$ N VIEW). Surfaces between which view factors are omitted are assumed to have view factors of zero. 


\subsection{PIECEIHSE LINEAR CURVE DATA}

\section{Card 1}

\section{Columns}

$1-10$

$11-15$

$16-20$

1-10

$11-20$

NOTES:

\begin{tabular}{clll} 
Columns & Format & Entry & Note \\
\hline $1-10$ & E10.0 & Time or temperature & 2 \\
$11-20$ & E10.0 & Funetional value &
\end{tabular}

Format

A10

I5

15

Entry

Note

Curve identification

Curve number

1

Number of points in curve (NPTS)

Card 2

Repe日t for NPTS Points

2. Curve point coordinates must be in order starting with the lowest time or temperature. 


\subsection{BLOCK TIME STEP OPTION}

\section{Card 1}

Columns 1- 7

Columns

1-10

11-20

NOTES:
Format

A7

Entry

Note

Word "NEWSTEP"

1

\section{Card 2}

Format

Entry

Note

E10.0 New time step size (DT)

2

E10.0 New maximum time (TMAX)

3. The printing and plotting intervals specified on Control Card No. 3 remain unchanged. Temperctures at the end of the firs: new time step and at the new maximum time will always be printed and plotied unless suppressed by giving negative intervals on Control Card No. 3. 
columns

$1-7$

Format

A7
Entry

Word "NFWFIJE"
Note

1

NOTE: 1. After exeeution TACO will attempt to read a new title card. If it finds this entry, it will ercate a new input file named NEWFILE which is identieal to the original input file except that the initial time and time step size are set to the current values and the initial temperatures on the nodal eards (Section 5.3) are replaced by the current temperatures. The user can then restart the solution with this input file. 


\subsection{INTERACTIVE CONTROLS}

Several interactive controls are available to the user when executing TACO via teletype. These controls allow the user to query the status of the code execution, to change time step size, or to terminate execution. The controls are utilized by typing keywords in a left-justified alphanumeric (A7) format. A list of keywords and their corresponding teletype responses follows.

Keyword

TIME

TIMES

NOTIMES

NODES

NONODES

NEWSTEP

STOP

ABORT

\section{$\underline{\text { Response }}$}

Current time, time step size, and step number

Time, time step size, and step number at the present and each following step Turns off effect of "IIMES"

Same as "TIMES" except that user is initially prompted from one to five node numbers whose temperatures are also typed out at each time step

Turns off effect of "NODES"

Same as "NEWSTEP" option in Section 5.15 except teletype prompts for new time step size and maximum time which are then utilized starting at the next time step Execution is terminated immediately in normal mode as with "STOP" card in Section 5.1

Execution is terminated immediately in error mode with drop file retained 


\section{EXAMPLES}

In this section the solutions for two example problems are shown. These problems were purposely chosen to have small numbers of elements and yet illustrate several of the capabilities of TACO. Both examples have exact solutions with which the numerieal results can he compared.

\subsection{EXAMPLE NO. 1}

This a nonlinear, one-dimensional, stendy-state problem which can be stater mathematically as follow's:

$$
\begin{array}{ll}
\frac{\mathrm{d}}{\mathrm{dx}}\left(\mathrm{k} \frac{\mathrm{d} \theta}{\mathrm{dx}}\right)+Q=0 & 0 \leq \mathrm{x} \leq \mathrm{L} \\
k=\mathrm{A}+\mathrm{B} \theta & \\
-k \frac{\mathrm{d} \theta}{\mathrm{dx}}=C\left(\theta^{4}-\theta_{\infty}^{4}\right) & \text { at } \mathrm{x}=0 \\
\theta=\theta_{l} & \text { at } \mathrm{x}=\mathrm{L}
\end{array}
$$

For the set of numerieal values
$\mathbf{L}=\mathbf{1}$
$r=0.0025$
$A=1$
$\theta_{\infty}=4$
$B=-0.2$
$\theta_{\mathrm{L}}=1$
$Q=0.2$

the exact solution is

$$
\theta=2-x
$$




\section{EXAMPLES (cont'd.)}

A finite element mesh with only two elements was used in the analysis. This mesh and the TACO input data used to this problem are shown in Figures 6.I and 6.2.

Note that TACO requires a single layer of two-dimensional elements to analyze this problem. The problem is made one-dimensional by making the sides parallel to the $x$-axis adiabatic. TACO defaults to the adiabatic boundary condition and, thus, such canditions need not be specified in the input data.

In order to ilustrate the convergence of the solution, the temperatures at $x=0.0$ and $x=0.5$ for each iteration are shown in the following table:

\begin{tabular}{|cll|}
\hline $\begin{array}{c}\text { ITERATION } \\
\text { NUMBER }\end{array}$ & \multicolumn{2}{c|}{ TEMPERATURE } \\
\hline 0 & $=0.0$ & $x=0.5$ \\
1 & 0.0 & 0.0 \\
2 & 1.500 & 1.275 \\
3 & 1.853 & 1.446 \\
4 & 1.955 & 1.484 \\
5 & 1.986 & 1.495 \\
6 & 1.996 & 1.499 \\
7 & 1.999 & 1.500 \\
& 2.000 & 1.500 \\
\hline
\end{tabular}




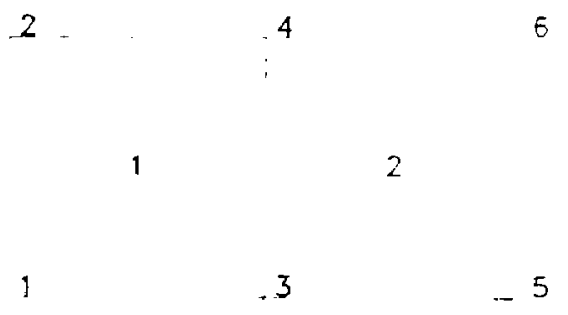

F1GURE 6.1. MESH FOR EXAMPLE NO. 1

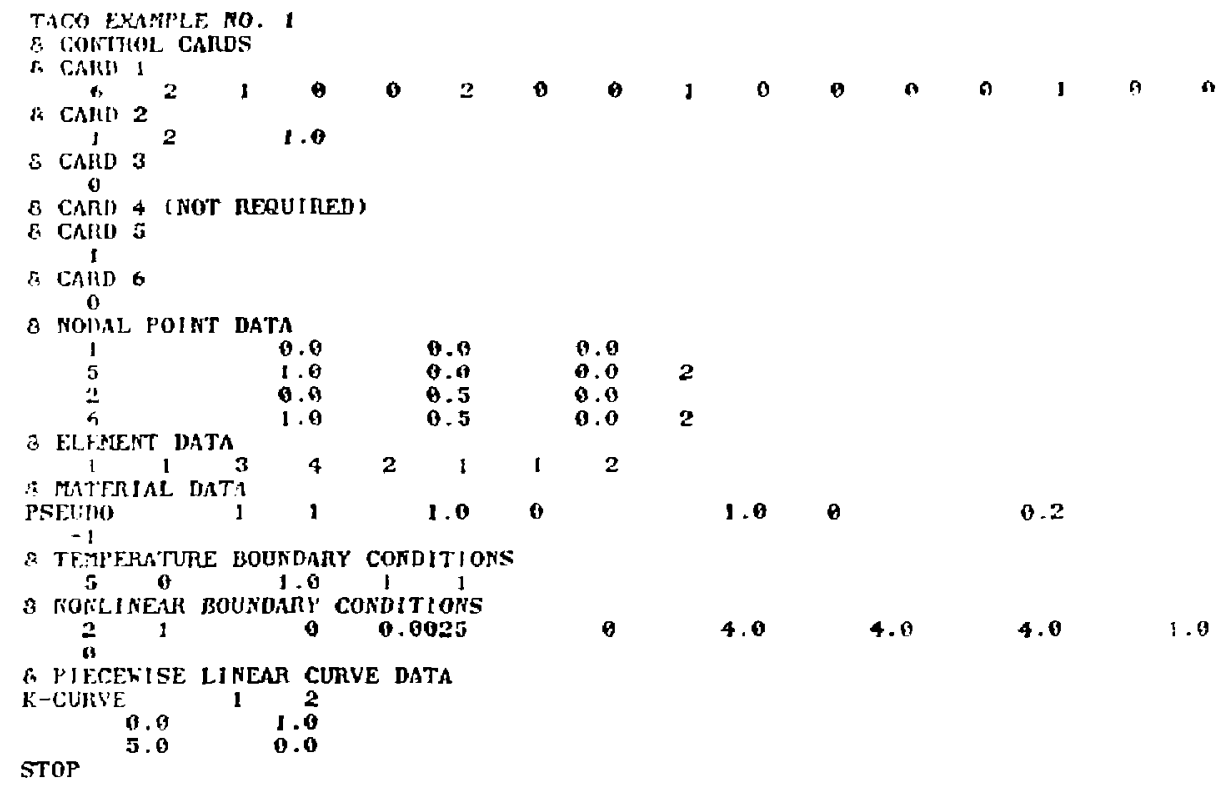

FIGURE 6.2. INPUT DATA FOR EXAMPLE NO. 1 


\section{EXAMPLES (cont'd.)}

\subsection{EXAMPLE NO. 2}

This is a linear, one-dimensional, transient problem. It is stated methematically as follows

$$
\begin{aligned}
& \rho c_{p} \frac{\partial \theta}{\partial t}=\frac{\partial}{\partial x}\left(k \frac{\partial \theta}{\partial x}\right) \quad 0 \leq x \leq L \\
& \theta(0, t)=\theta_{0} \\
& -k \frac{\partial \theta}{\partial x}(L, t)=h\left[\theta(L, t)-\theta_{\infty}\right] \\
& \theta(x, 0)=\theta_{0}
\end{aligned}
$$

The exact solution is

$$
\begin{aligned}
\theta(x, t) & =\theta_{0}-\left(\theta_{0}-\theta_{\infty}\right)\left(\frac{H}{1+H}\right)\left(\frac{x}{L}\right) \\
& +2 H\left(\theta_{0}-\theta_{\infty}\right) \sum_{n=1}^{\infty} \frac{\sin \lambda_{n} L \sin \lambda_{n} x}{\left(\lambda_{n} L\right)^{2}+H \sin ^{2} \lambda_{n} L} e^{-\lambda_{n}^{2} \alpha t}
\end{aligned}
$$

where

$$
\begin{aligned}
& \alpha=\frac{k}{D c_{p}} \times \text { thermal diffusivity } \\
& H=\frac{h L}{k}=\text { Biot number }
\end{aligned}
$$




\section{EXAMPLES (cont'd.)}

and $\lambda_{n}$ is obtained from

$$
\left(\lambda_{n} L\right) \cot \left(\lambda_{n} L\right)=-H
$$

The following specific numerical values were chosen for the analysis:

$$
\begin{gathered}
\rho=c_{p}=k=L=\theta_{0}=1 \\
\theta_{\infty}=0 \\
h=0.6
\end{gathered}
$$

A five element mesh was used to analyze this problem. This mesh and the input data for one solution case are shown in Figures 6.3 and 6.4.

Figures 6.5 and 5.5 are time history plots at $x=1$ for $\Delta t=0.10$ and $\Delta t=0.05$. Each plot contains curves obtained using $\alpha=0.5$ (Crank-Nicholson) and $\alpha=1.0$ (backward implicit) in addition to the exact solution curve.

Figure 6.7 is a plot of temperature versus position at time $t=0.1$ for the $\Delta t=0.1$ solution. Both the $\alpha=f .5$ and $\alpha=1.0$ curves are plot ted as is the exact solution. 


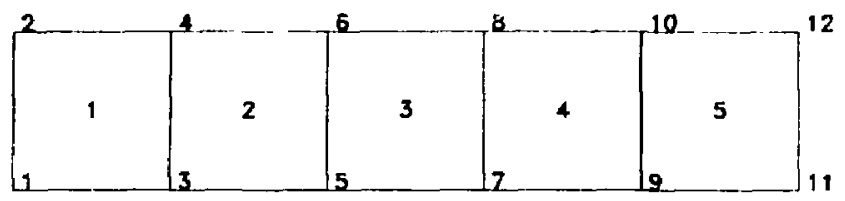

FIG!RE 6.3. MESH FOR EXAMPLE NO. 2

TACO EXAKPLE No. 2

3 ComTrol cand No. 1 3 CoNTfOL CARD Ko. 2 $12^{2}$ 3 CONTROL CARD NO. 3 - $\operatorname{cohmoL}^{\prime} \operatorname{cano}^{1}$ No. 3 CONTROL CARD NO. 5 $\theta$ 3 coNTHOL CARD No. 6

a MODAL DATa

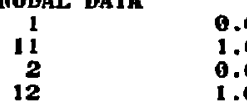

$\begin{array}{llll}0.0 & 0.0 & 0.0 & \\ 1.0 & 0.0 & 0.0 & 2 \\ 0.0 & 0.2 & 0.0 & \\ 1.0 & 0.2 & 0.0 & 2\end{array}$

a ELEMENT DATA ilerial Data PSEUDO 1 8 TEMPERATURE BOUNDARY CONDITIONS 8 COIVECTION BOUNDARY CONDITIONS 110.6 STOP

FIGURE 6.4. INPUT DATA FOR EXAMPLE NO. 2 


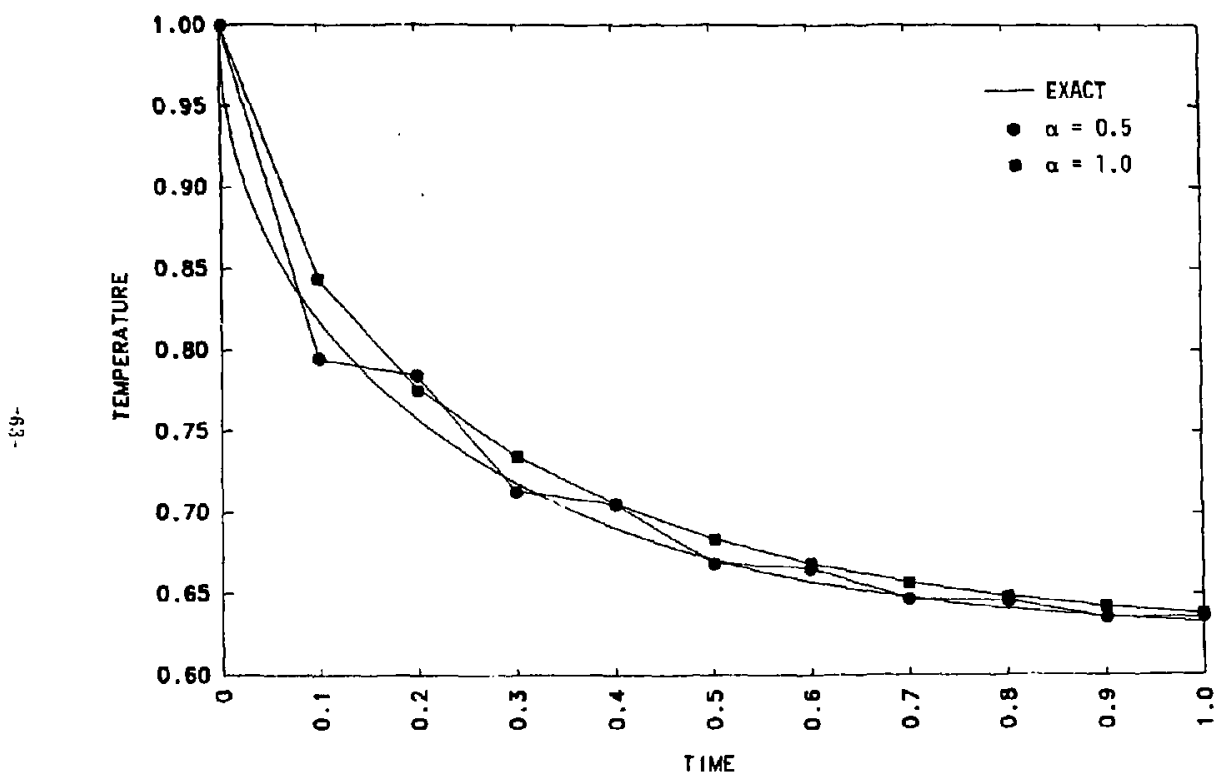

FIGURE 6.5. TIME HISTORY AT $X=1$ FOR $\Delta \mathrm{t}=0.1$ 


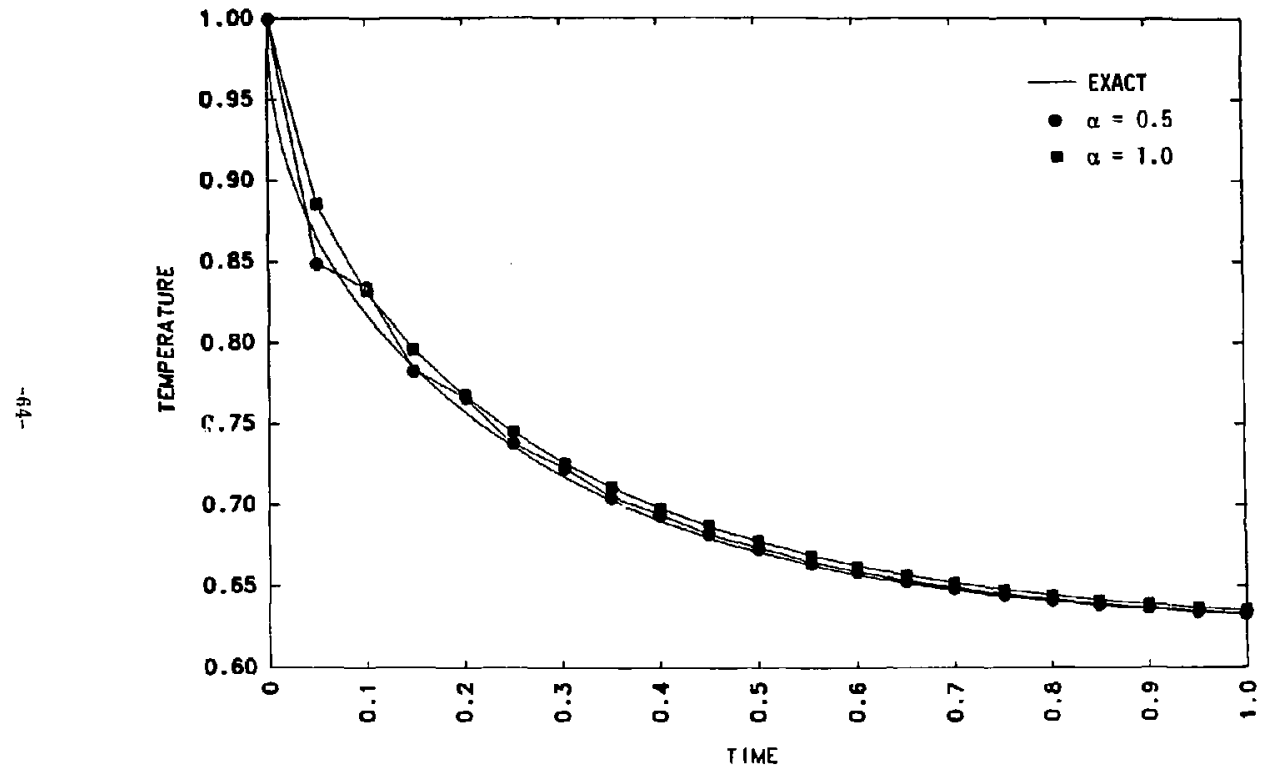

FIGURE 6.6. TIME HISTORY AT $X=1$ FOR $\Delta t=0.05$ 


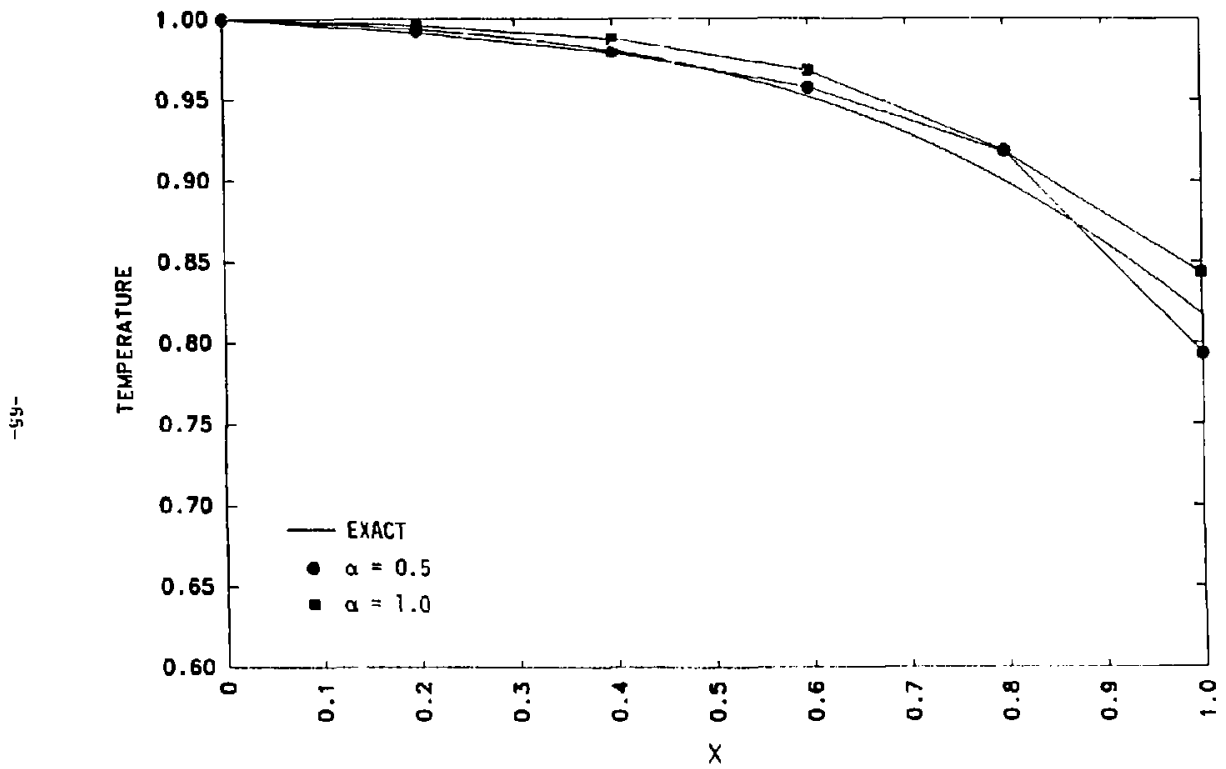

FIGURE 6.7. TEMPERATURE VERSUS POSITION AT TIME $\mathrm{t}=0.1$ FOR $\Delta \mathrm{t}=0.1$ 


\section{ACKNOWLEDGEMENT}

The author wishes to thank Jerry (ioudreata and Join Hallquist of the Methods Development Group and Steve Sackett of the Nuclear Explosives Engincering Division who have each contributed in some way to the development of TACO. Special thanks is die Nikki Falco of MDG who tvped this report and nttended to all the details of getting it printed and distributed. Thanks is a!so given to Dale Schauer of the Nuclear Explosives Engineering Division and Bob Bailey of the Weapons Engineering Division for their many helprul suggestions. 


\section{RFFERENCES}

1. W. T. Mason, "POSTACO - A Post-Processor for Scalar Finite Flement Codes," Lawrence Livermore Laboratory, UCID-17980, Rev. 1 (1980).

2. O. C. 7ienkiewicz, The Finite Element Method, 3rd Ed., MeGraw-Hill, 1977.

3. T. J. R. Hughes, "Stability of One-Step Methods in Transient Nonlinear Hent Conduction," Transactions of the tth International Conference on Struetura! Mechnnics in Nucleur Reactor Technology, San Franeiseo, Californin, No. i3 2/10, August $197 i$.

4. $\quad$ 1. J. Burger, "ZONE - A Finite Flement Mesh Generator," Lavirenen Livermore l,aboratory, UCID)-17139 (197(j).

5. M. A. Gerhard, "SI.IC: An Interactive, Graphic Vesh Generator for Finite-Element and Finite-Differener Applieation Programs," Lnwrence Livermore Laboratory, UCRL-52823 (197?).

6. S. J. Sackett and R. L. Tayior, "FISSLE - A Fast Implicit Solver for Systems of Linear Equations," (in publication).

7. J. O. Hallquist, "NIKE2D - An Implicit, Finite Deformation, Finite Element Code for Analyzing the Static and Dynamic Response of 2-D Solids," Lawrence Ljvermore Laboratory, UCRI,-52678 (1979).

8. N. E. Gibbs, W. G. Poole, and P. K. Stockıneyer, "An Algorithm for Reducing the Bandwidtl and Profile of a Sparse Matrix," SIA J Journal of Numerical Analysis, Vol. 13, No. 2, April I976, pp. 236-250. 


\section{APPENDIX A}

\section{USER SUBPROGRAM}

As mentioned in Section ?.15, a user subprogram ontion is availahle in TACO. This ontion allows the user to write a separate suhbrogram with which to calculate functional values of quantities such as material pronerties and houndarv conditions. This innv he necessarv in cases where the use of piecewise linear eurves or constants as described in Seetion 2.14 are not sufficient or too eumbersome for deseribing n particular funetion. The purpose of this appendix is to explain how this ontion is implemented in TACO.

Functions defined hy a user subprogram are handled in the same way as piecewise linear curves in that "eurve" numhers are used to indicate which function is heing evaluated. Positive curve numbers indicate funetions of time and negative surve numbers indiegte functions of temperature. In order to distinguish a function provided hy a user subprogram, the curve number must be greater than 999 (in nhsolute value'.

The user suhprogram must 'se named "USUB" and must have five entrv points including the call to USUB. The entru point names and their purposes are as follows:

USUB : To initialize and read data.

USUB2 : To ealculate functional values.

USUB3 : To Ipdate variahles which mav not be common to TACO. For example, in chemical kinetics calculations, the reactant concentrations mav be calculated in the user suhprogram whereas TACO only requires the heat generated by the reactive process.

USUB4 : To print results of user subprogram calculations at desired intervals.

USUBS : To plot results of user subprogram calculations at desired intervals. 
Anv of the entry points mav he dummy entries (i.e., enter sutsprogram and return).

A simple exnmple of a user subprogram is shown in the following listing (Note: some eompilers such as CFT on the CBAY computers require the argument list to appear with marh entry statement, r.g.. entry USUB? (N,F,F)h:

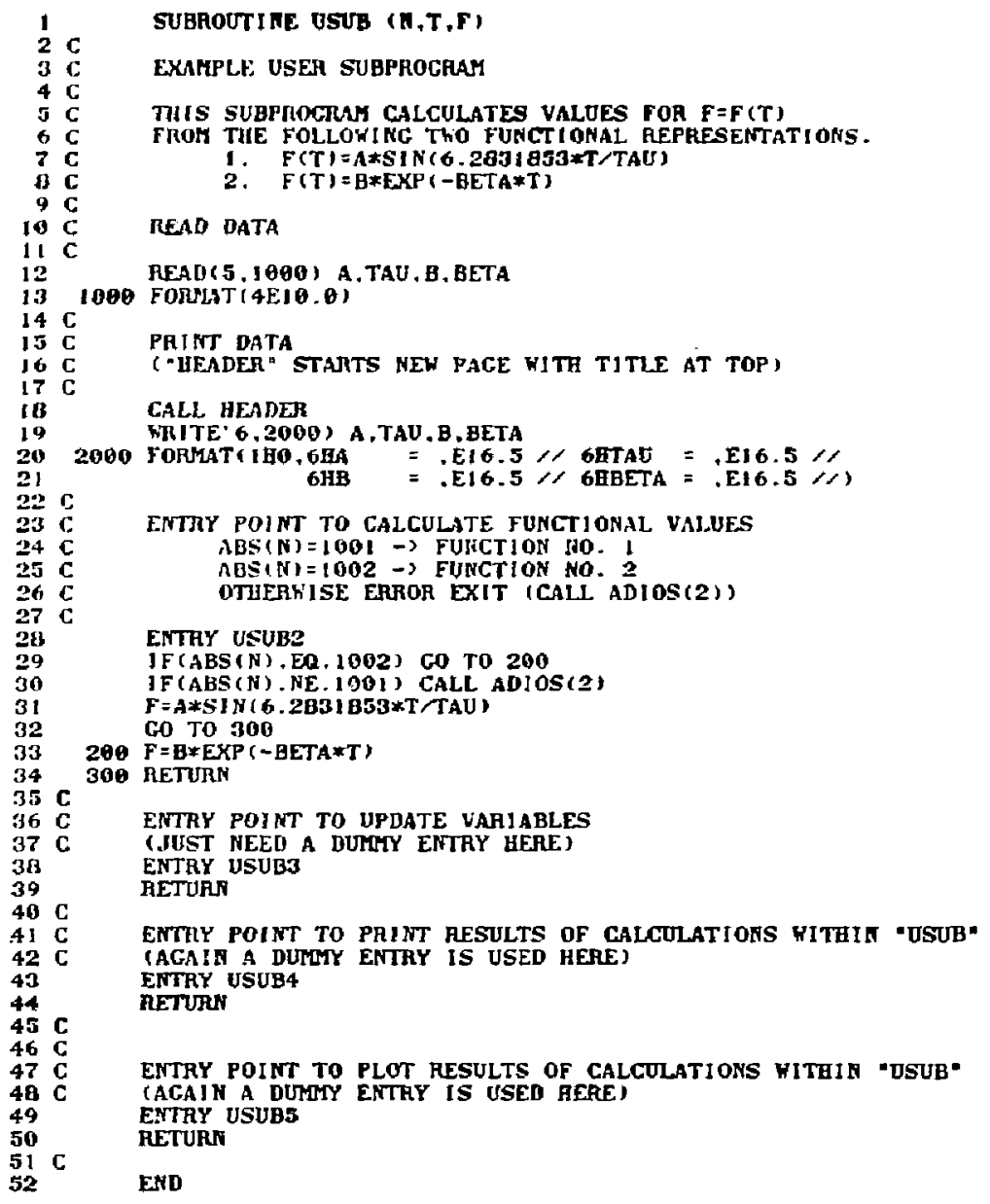


Once the source file for USUB has been created, it must be compiled and then loaded with the necessary TACO binary files to obtain a controllee. This can be necomplished as follows:

1. Obtain the file TACORUN from storage on the CDC7600 computers with

EXE GLGLIB TACORUN DR. / $t v$

and on the CRAY computers with

LIB MDGLIB!X TACORUN!END / $t \mathrm{v}$

2. Compile USUB and ereate new TACO controllee on the CDC7600 computers with TRIX AC!O(TACORUN)!RUN!END / $t v$

and on the CRAY computers with

\section{TRIXGL!O(TACORUN)!RUN!END / $\mathrm{t} v$}

The above steps will result in the automatic execution of several routines. These routines read files from storage as they are needed and destroy them when they are no longer required. Upon the successful completion of Step 2, the following files will remain:

TACO : A new controllee incorporating the user's subprogram

TACOM: The load map for TACO

TACO*: The symbol table for TACO

USUB : The user subprogram source

BSUB : The binary file for USUB

LSUB : The list file for USUB 


\section{APPENDIX B}

\section{ENCI,OSURE RADIATION}

\section{B.1. INTRODUCTION}

TACO has the capability to solve problems of conduction in a solid coupled with radiation in enclosures within the solid. Presently, only enclosures bounded by diffuse-gray surfaces con be treated. Also, only two-dimensional geometries (planar or axisymmetric) can be analyzed. This appendix briefly deseribes the theoretical basis for enelosure radiation and explains how the theory is implemented in TACO.

\section{B.2. BASIC THEORY}

The basis for the analysis of enclosure radiation as performed by TACO is the net-radiation method. This method is described in detail by Siegel and Howell (1).

In TACO an enclosure is defined by the $\mathrm{N}$ discrete surfaces which are, in general, the boundaries of the elements which stirround the enclosure as illustrated in the following figure.

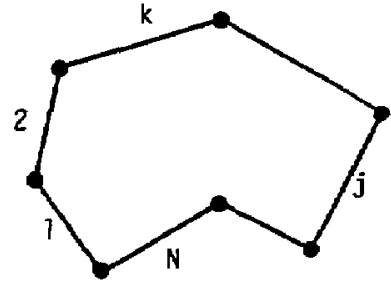




\section{ENCLOSURE RADIATION (cont'd.)}

The basis functions for the elements surrounding an enclosure are such that the temperature on an element boundary varies linearly between nodal points.

However, for purposes of the enclosure radiation analysis, it is convenient to assign a constant value of temperature to each discrete enclosure surface. This temperature is obtained by averaging the values the two nodes defining each enclosure surface.

Assuming that the temperature of each enclosure surface is known, Siegel and Howell (1) derive the following equations:

$$
\begin{aligned}
\sum_{j=1}^{N}\left[\delta_{k j}-\left(1-\epsilon_{k}\right) F_{k-j}\right] q_{0, j}=\epsilon_{k} \sigma \theta_{k}^{4} \\
q_{j, k}=\sum_{j=1}^{N} F_{k-j} q_{0 . j} \\
q_{k}=q_{0, k}-q_{i, k}
\end{aligned}
$$

where

$$
\begin{array}{ll}
\theta_{k} & =\text { absolute temperature of surface } k \\
q_{0, k} & =\text { outgoing radiant energy per unit area (radiosity) from surface } k \\
q_{j, k} & =\text { incoming radiant energy per unit area to surface } k \\
q_{k} & =\text { net energy fux leaving surface } k \\
\epsilon_{k} & =\text { emissivity of surface } k \\
\mathbf{F}_{\mathbf{k}-\mathbf{j}} & =\text { view or configuration factor from surface } k \text { to surface } \mathbf{j} \\
\boldsymbol{\delta}_{\mathbf{k j}} & =\text { Kronecker delta } \\
\boldsymbol{\sigma} & =\text { Stefan-Boltamann constent. }
\end{array}
$$


In order to ohtain the net energv flux $q_{k}$ for surface $k$, the series of linear algebraic equations represented hv Eq. (B.1) must first be solved for the radiosities $q_{0, j}(j=1,2, \ldots, N)$. Equations $(B .2)$ and $(B .3)$ then combine to give $q_{k}$.

The ahove procedure is used hv TACO to solve the radiation part of the counled prohlem. At each time step, Equations (B.1-B.3) are solved using the $\theta_{k}$ values estimated from the previous time sten. The resulting fluxes $q_{k}$ are then used as houndarv conditions for the solution of the conduction problem. This solution then gives new estimates for the surface temperatures $\theta_{k}$. The process is then repeated until convergence is achiever. The solution then proceeds to the next time sten.

The series of equations represented bv Eq. 'B, 1 ' is solved by Geuss-Seidel iteration rather than hy a direct method. This method of solution appears to work well and has the advantage of saving considerable computer storage.

\section{B.3. VIEW FACTORS}

The view or configuration factors required in Eq. (B.1) are normally calculated bV TACO. However, the option to input view factors is availahle should the user desire to do so. In order to properly calculate the view factors TACO requires that the nodes describing the enclosure surfaces be input in order as they andear when proceeding clockwise around the enclosure (see Section 5.14).

\section{B.4 SYMMETRY}

When planes of symmetry are used to reduce the size of a problem, the condurtion "boundarv conditions" become $q=0$ (i.e., adiabatic). However, in the case of enclosure radiation, a plane of symmetry does not imply that $q=0$. In this case the symmetry plane acts like a mirror reflecting radiant energy back to the mirror images of surfaces hevond the plane as illustrated below. 


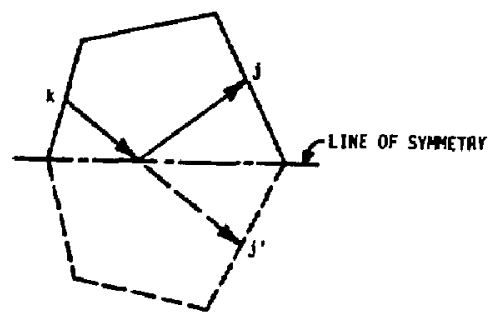

TACO will account for this mirror effect of a symmetry plane. However, the user must describe the location of the symmetry planes in the input (Section 5.14).

\section{B.5 INSULATED SURFACES}

An insulated surface on an enclosure boundary can be defined by giving that surface an emissivity $\epsilon=0$. Otherwise, such a surface is treated the same as any other.

\section{B.6 OPENINGS}

When an enclosure has an opening to the exterior of a body, the opening acts like a nonreflective surface. Such a surface acts as a blackbody radiator $(\epsilon=1)$ at the outer surrounting temperature. Therefore an opening mav be specified in TACO by defining an enclosure boundary segment with $\epsilon=1$ and with a temperature equal to that of the outer surroundings.

\section{B.7 REFERENCES}

1. R. Siegal and J. R. Howell, "Thermal Radiation Heat Transfer," MeGraw-Hill, 1972. 


\section{APPENDIX C}

PLOT FILE DATA BASE

As deseribed in the section on execution, TACO creates a family of direct addressable binary plot files. The default length of each file is $1,000,000$ octal $(262,144$ decimal) words. The format for these files is as follows:

CONTROL SECTION (64 words, 8 characters per word)

Words

$1-10$

11

12

13

14

15

16

17

18

19

24

25

26

27-64

\section{Description}

Title of problem

Time of day when run was begun

Date of run

Letter designator for computer on which run was made Name of code ("TACO")

Compilation date of code

NDIM, number of dimensions (NDIM $=2$ )

NUMNP, number of nodal points

ICODE, post-processor code (ICODE=1)

NGLBV, number of global variables written with each state

(NGLBV $=0$ )

Blank

NUMEL, number of elements

NUMATS, number of materials

NUMST, number of states

Blank

\section{GEOMETRY SECTION（2*NUMNP+5*NUMEL Words）}

Words

$2 *$ NUMNP

5*NUMEL

\section{Description}

Array of nodal coordinates: $x_{1}, y_{1} x_{2}, y_{2}, \ldots$ or

$r_{1}, z_{1}, r_{2}, z_{2}, \ldots$

Element connectivity arrays and material numbers (MATN):

$\mathrm{N}_{1}, \mathrm{~N}_{2}, \mathrm{~N}_{3}, \mathrm{~N}_{4}$, MATN $)_{1},\left(\mathrm{~N}_{1}, \mathrm{~N}_{2}, \mathrm{~N}_{3}, \mathrm{~N}_{4}, \mathrm{MATN}\right)_{2}, \ldots$ 
PLOT FILE DATA BASE (cont'd.)

TIME STATE SECTION (NUMST*(NUMNP+1) Words)

NUMST states written as follows:

Words

1

NUMNP

\section{Description}

Time

Nodal point temperatures at this time: $\theta_{1}, \theta_{2}, \ldots$ 